FRBSF Working Paper \#2003-10

\title{
Robust Monetary Policy with Competing Reference Models
}

\author{
Andrew T. Levin \\ Board of Governors of the Federal Reserve System \\ John C. Williams \\ Federal Reserve Bank of San Francisco
}

First Version: November 2002

Current Version: July 2003

KEYwords: Model uncertainty, robust control, optimal control, Bayesian control.

JEL Classification System: E31, E52, E58, E61

Correspondence:

Levin: Federal Reserve Board, 20th and C Streets NW, Washington, DC 20551, USA; 202-452-3541; andrew.levin@frb.gov

Williams: Federal Reserve Bank of San Francisco, 101 Market Street, San Francisco, CA 94105, USA 415974-2240; john.c.williams@sf.frb.org

* We thank Richard Dennis, Peter Ireland, Ben McCallum, Glenn Rudebusch, Lars Svensson, Volker Wieland, Noah Williams, and participants at presentations at the Federal Reserve Bank of San Francisco, University of California, Davis, the Impulse and Propagation Mechanisms Group Summer Institute meeting, the Winter Econometric Society meeting, and the Carnegie-Rochester Conference Series on Public Policy for helpful comments and suggestions. The views expressed in this paper are solely the responsibility of the authors and should not be interpreted as reflecting the views of the Board of Governors of the Federal Reserve System, or the management of the Federal Reserve Bank of San Francisco, or the views of any other person associated with the the Federal Reserve System. We thank Kirk Moore for excellent research assistance and Judith Goff for editorial assistance. Any errors are the sole responsibility of the authors. 


\begin{abstract}
The literature on robust monetary policy rules has largely focused on the case in which the policymaker has a single reference model while the true economy lies within a specified neighborhood of the reference model. In this paper, we show that such rules may perform very poorly in the more general case in which non-nested models represent competing perspectives about controversial issues such as expectations formation and inflation persistence. Using Bayesian and minimax strategies, we then consider whether any simple rule can provide robust performance across such divergent representations of the economy. We find that a robust outcome is attainable only in cases where the objective function places substantial weight on stabilizing both output and inflation; in contrast, we are unable to find a robust policy rule when the sole policy objective is to stabilize inflation. We analyze these results using a new diagnostic approach, namely, by quantifying the fault tolerance of each model economy with respect to deviations from optimal policy.
\end{abstract}




\section{Introduction}

Most studies of the problem of formulating monetary policy under uncertainty about the true structure of the economy have followed Brainard (1967) in focusing on the case in which the policymaker has a single reference model and the true economy lies within a specified neighborhood of this model. For example, Hansen and Sargent (2002) provide a rigorous treatment of robust control in the face of uncertainty about the data-generating process, or DGP, of the exogenous disturbances. Giannoni (2001, 2002) characterizes rules that are robust to uncertainty about the estimated parameters, while Onatski and Stock (2002) and Onatski and Williams (2003) analyze the robustness of simple rules when the behavioral equations of the model are subject to misspecification errors; these papers also consider uncertainty about the shock process. Finally, Svensson (1997) and Giannoni and Woodford (2003) have emphasized that the optimal targeting rule for a given model has a representation that is invariant to known changes in the shock process and contend that this is the primary sense in which a proposed rule should be robust. ${ }^{1}$

In this paper, we analyze the robustness of policy rules when non-nested models represent competing perspectives about controversial issues such as expectations formation and inflation persistence. ${ }^{2}$ Such an approach was initially advocated by McCallum (1988) and seems consistent with the aims of Taylor (1993a), whose simple policy rule was intended to yield reasonable macroeconomic stability under a wide range of assumptions about the "true" structure of the economy. ${ }^{3}$ One interpretation of this approach, suggested by Patrick Minford, is related to the decision-making of a policymaking committee. Each committee member holds a particular view of the behavior of the economy, represented by a macro model. A robust rule is one that, although not exactly optimal for any committee member, yields outcomes that are acceptable to all committee members. A nonrobust rule, in contrast, is one that performs very poorly in at least one of the committee members' models and thus interferes with the building of a consensus view of policy.

We consider three distinct macroeconomic models, two of which have been scrutinized in the robust control literature. First is a benchmark version of the New Keynesian model (henceforth denoted NKB, for New Keynesian Benchmark), which has been studied by Hansen and Sargent (2002), Giannoni (2001, 2002), and Giannoni and Woodford (2002b); this model has purely forward-looking specifications for price setting and aggregate demand and exhibits no intrinsic persistence. ${ }^{4}$ Second

\footnotetext{
${ }^{1}$ For further analysis and discussion of optimal targeting rules, see Svensson (2003), and Svensson and Woodford (2003a).

${ }^{2}$ For other analyses of monetary policy under this form of model uncertainty, see Karakitsos and Rustem (1984), Becker, Dwolatsky, Karakitsos and Rustem (1986), Frankel and Rockett (1988), Holtham and Hughes-Hallett (1992), Christodoulakis, Kemball-Cook and Levine (1993), Levin, Wieland and Williams (1999), and Levin, Wieland and Williams (2003).

${ }^{3}$ See McCallum (1999) for a further discussion of robustness to model uncertainty.

${ }^{4}$ See the analysis and discussion in Clarida, Gali and Gertler (1999) and Woodford (2000), who also provide references to the extensive literature related to this model.
} 
is the Rudebusch and Svensson (1999) macroeconometric model, which has purely backward-looking structural equations and very high intrinsic persistence; this model (henceforth denoted as the RS model) served as the benchmark in the analysis of Onatski and Stock (2002) and Onatski and Williams (2003). Third is a model taken from Fuhrer (2000) and denoted as the FHP, for FuhrerHabit-Persistence, model-utilizes rational expectations but exhibits substantial intrinsic persistence of aggregate spending and inflation. In all three models, the short-term nominal interest rate is assumed to be the monetary policy instrument. Throughout the analysis, we assume that the policymaker's objective is to minimize a weighted sum of the unconditional variances of the inflation rate, the output gap, and the change in the short-term nominal interest rate.

We begin by demonstrating that the robust control rules proposed in the literature are not necessarily very robust to model uncertainty; that is, a rule obtained from a given reference model may perform very poorly in other models. This potential pitfall of robust control was anticipated by Sargent (1999), who noted that the perturbations of the exogenous shock process comprise only a fairly restrictive set of potential model misspecifications, because the perturbed shocks still feed through the system just as in the reference model. Thus, while the approach of Giannoni and Woodford (2002a) yields a policy rule that is invariant to the characteristics of the shock process, the optimal control rule does embed the structure of endogenous relationships of the reference model, and hence we find that such rules may generate poor or even disastrous outcomes when implemented in another model with markedly different endogenous relationships.

More generally, our results suggest that focusing on specification errors or parameter uncertainty in the neighborhood of a particular reference model may dramatically understate the true degree of model uncertainty. ${ }^{5}$ For example, Giannoni (2001) quantifies the parameter uncertainty of the NKB model by using the estimated standard errors of Amato and Laubach (2003) and obtains rules that involve a very high degree of interest rate smoothing. Unfortunately, we find that such "super-inertial" rules typically yield very poor performance in the presence of substantial intrinsic persistence (as in FHP) and generate dynamic instability under the assumption of adaptive expectations (as in RS). ${ }^{6}$ Evidently, the degree of uncertainty due to sampling variation is relatively small compared with the uncertainty associated with various choices about model specification, estimation technique, etc.

Next, using Bayesian and minimax methods, we investigate how well simple policy rules perform across the three competing reference models. In particular, we focus on the class of 3-parameter rules in which the short-term nominal interest rate is adjusted in response to its own lagged value as well as to the current output gap and inflation rate. For a given choice of objective function weights, we determine the policy parameters that minimize the average loss across the three models

\footnotetext{
${ }^{5}$ This potential pitfall of robust control methods has been emphasized by Sims (2001).

${ }^{6}$ Rudebusch and Svensson (1999) have previously identified the dynamic instability of super-inertial rules in their model.
} 
(the Bayesian strategy with flat prior beliefs about the accuracy of the three models), and then we determine the parameters that minimize the maximum loss across the three models (the minimax strategy).

Using a similar approach, Levin et al. (1999) showed that first-difference rules-that is, rules with a coefficient of unity on the lagged interest rate-provide robust performance across a fairly wide range of rational expectations models. ${ }^{7}$ However, Sargent (1999) has noted that those "comforting" results might primarily reflect the relative proximity of the models, and, in fact, Rudebusch and Svensson (1999) find that first-difference rules (and super-inertial rules) typically generate dynamic instability in the RS model. Thus, as Taylor (1999) concludes, the remaining challenge has been to identify rules that yield robust performance in both forward-looking and backward-looking models.

We find that simple rules incorporating a moderate degree of interest rate smoothing yield remarkably robust performance in all three reference models as long as the loss function places nontrivial weight on stabilizing both output and inflation. In contrast, under strict inflation targeting, no simple rule yields robust performance across all three models.

Finally, we interpret these results using a new diagnostic approach, namely, by analyzing the fault tolerance of each model economy with respect to deviations from optimal policy. For example, when the loss function assigns substantial weight to both output and inflation volatility, we find that the NKB model exhibits a very high degree of fault tolerance: although the optimal rule for this model is super-inertial, the use of a rule with moderate inertia does not cause a severe deterioration in stabilization performance. The RS model exhibits much less fault tolerance; that is, the loss function has much greater curvature, especially with respect to deviations in the interest rate smoothing parameter (which has an optimal value close to zero). Thus, while super-inertial rules generate dynamic instability in this model, rules with moderate policy inertia perform nearly as well as the optimal rule.

The remainder of this paper proceeds as follows. Section 2 describes the key properties of the three competing models. Section 3 documents the lack of robustness of rules designed to work well in the neighborhood of a specific model. Section 4 describes the performance of simple rules obtained by applying Bayesian and minimax methods to the set of competing models. Section 5 defines measures of fault tolerance and then uses these tools to interpret our results. Section 6 extends the analysis to incorporate a number of other macroeconomic models. Section 7 summarizes our conclusions and considers directions for further research.

\footnotetext{
${ }^{7}$ See also Levin et al. (2003).
} 


\section{Three Competing Reference Models}

To consider the policy implications of competing reference models, we consider three distinct macro models. Each model incorporates a combination of long-run monetary neutrality and short-run nominal inertia, so that monetary policy has a potentially significant role in stabilizing the economy. Furthermore, each model is intended to provide a plausible representation of the dynamic behavior of the U.S. economy, using parameter values that have been estimated or calibrated to match particular features of quarterly macro data. Nevertheless, the three models represent very different perspectives about expectations formation and other structural characteristics of the economy.

The behavioral equations of the NKB model can be derived from formal microeconomic foundations. We calibrate the NKB model according to the parameter values given in Woodford (2000), simply adjusting these values to account for the fact that our variables are expressed at annual rates in percentage points. The resulting specification is given by:

$$
\begin{aligned}
\pi_{t} & =0.99 E_{t} \pi_{t+1}+0.096 y_{t}+\epsilon_{t} \\
y_{t} & =E_{t} y_{t+1}-1.59\left(i_{t}-E_{t} \pi_{t+1}-r_{t}^{*}\right)
\end{aligned}
$$

where $\pi$ denotes the inflation rate, $y$ denotes the output gap (the deviation of output from potential), $i$ denotes the short-term nominal interest rate, and $r^{*}$ denotes the equilibrium real interest rate. The operator $E_{t}$ indicates the model-consistent forecast of a particular variable, using information available in period $t$. We use the calibration of the exogenous disturbances given in Levin et al. (2003). In particular, $r_{t}^{*}$ follows an AR(1) process with autocorrelation parameter 0.35, and its innovation has a standard deviation of 3.72. The aggregate supply shock $\epsilon_{t}$ is i.i.d., and its standard deviation is chosen so that the unconditional variance of inflation under the benchmark estimated policy rule matches the sample variance of U.S. quarterly inflation over the period 1983:1-1999:4.

Output and inflation in the NKB model are purely forward-looking with no intrinsic persistence; that is, this model embeds the perspective that persistent output and inflation fluctuations are solely due to the persistence of the exogenous disturbances hitting the economy. ${ }^{8}$ For example, repeated forward substitution of equation (1) indicates that the current inflation rate is determined by current and expected future values of the output gap and of the aggregate supply shock, $\epsilon_{t}$. Furthermore, as shown by Kerr and King (1996), repeated forward substitution of equation (2) yields an "expectational IS curve" in which the current output gap is solely determined by the deviation of the ex ante long-term real interest rate from its equilibrium value. Thus, as emphasized by Woodford (1999), expectations about movements in future short-term rates are crucial in determining the performance of a particular monetary policy rule.

The RS model represents a very different modeling strategy, namely, imposing a set of empirically reasonable restrictions on the coefficients of a small-scale vector autoregression (VAR):

\footnotetext{
${ }^{8}$ For further discussion of this issue, see Rotemberg and Woodford (1997) and Fuhrer (1997b).
} 


$$
\begin{aligned}
& \pi_{t}=0.70 \pi_{t-1}-0.1 \pi_{t-2}+0.28 \pi_{t-3}+0.12 \pi_{t-4}+0.14 y_{t-1}+\epsilon_{1, t} \\
& y_{t}=1.16 y_{t-1}-0.25 y_{t-2}-0.10\left(\bar{i}_{t-1}-\bar{\pi}_{t-1}\right)+\epsilon_{2, t}
\end{aligned}
$$

where $\bar{i}$ is the four-quarter average interest rate and $\bar{\pi}$ is the four-quarter average inflation rate; that is, $\bar{i}_{t}=0.25\left(i_{t}+i_{t-1}+i_{t-2}+i_{t-3}\right)$ and $\bar{\pi}_{t}=0.25\left(\pi_{t}+\pi_{t-1}+\pi_{t-2}+\pi_{t-3}\right)$.

In contrast to the NKB model, these behavioral equations are purely backward-looking and embed a relatively high degree of intrinsic persistence. The lagged values of inflation in equation (3) can be interpreted as representing adaptive inflation expectations (cf. Rudebusch and Svensson (1999)); as a result of these lags, inflation is a fairly slow-moving state variable rather than a nonpredetermined "jump" variable (as in the NKB model). Similarly, equation (4) may be viewed as an IS equation in which the output gap responds to the ex post long-term real interest rate, $\bar{i}-\bar{\pi}$. As a result, monetary policy faces a substantial transmission lag in this model: an innovation to the empirical interest rate reaction function has no contemporaneous effect on output or inflation, and its peak impact does not occur until several years later. And of course, expected future policy plays no role at all in this model.

Finally, the FHP model represents an intermediate modeling strategy that seeks to balance rigorous microeconomic foundations with empirical goodness-of-fit. In this model, the inflation rate responds to a combination of forward-looking and backward-looking terms, a specification that may be interpreted in terms of overlapping relative real contracts (as in Buiter and Jewitt (1981)) or indexation of contracts to the lagged inflation rate (as in Christiano, Eichenbaum and Evans (2001)). In FHP, inflation is determined according to the following equations:

$$
\begin{aligned}
w_{t}-p_{t} & =E_{t} \sum_{j=0}^{3}(.37-.08 j)\left(\bar{v}_{t+j}+0.00252 y_{t+j}\right)+\epsilon_{w, t}, \\
p_{t} & =\sum_{j=0}^{3}(.37-.08 j) \bar{v}_{t-j}, \\
\bar{v}_{t} & =\sum_{j=0}^{3}(.37-.08 j)\left(w_{t-j}-p_{t-j}\right), \\
\pi_{t} & =400\left(p_{t}-p_{t-1}\right),
\end{aligned}
$$

where $w_{t}$ is the contract price, $p_{t}$ is the price level, and $\epsilon_{w, t}$ are serially uncorrelated shocks to the contract price.

Aggregate demand is derived in a setting with liquidity-constrained "rule-of-thumb" households as well as optimizing households with habit persistence in consumption. As a result, aggregate spending depends on current and lagged expenditures as well as on expected future income and the ex ante long-term real interest rate. Non-consumption output is determined by a reduced-form 
IS-curve relationship. The FHP model equations describing the determination of output are given by:

$$
\begin{aligned}
c_{t}-y_{t} & =0.741\left[\Omega_{y, t}-.669 \Omega_{z, t}-0.0028 \Omega_{q, t}-4.098 R_{t}\right]+\eta_{t}, \\
x_{t} & =1.003 x_{t-1}-0.126 x_{t-2}-1.011 R_{t-1}+\epsilon_{x, t}, \\
y_{t} & =c_{t}+x_{t} \\
\Omega_{y, t} & =E_{t}\left\{\Delta y_{t}+0.996 \Omega_{y, t+1}\right\} \\
\Omega_{z, t} & =E_{t}\left\{\Delta z_{t+1}+0.996 \Omega_{z, t+1}\right\} \\
\Omega_{q, t} & =E_{t}\left\{\Delta q_{t+1}+0.996 \Omega_{q, t+1}\right\} \\
z_{t} & =0.0015 z_{t-1}+0.9985 c_{t-1}, \\
q_{t} & =E_{t}\left\{\left(1.001 c_{t}-25.91 z_{t}\right)+.995 q_{t+1}\right\} \\
R_{t} & =E_{t}\left\{0.0244\left(i_{t}-\pi_{t+1}\right)+0.9756 R_{t+1}\right\} \\
\eta_{t} & =0.874 \eta_{t-1}+\epsilon_{\eta, t} .
\end{aligned}
$$

Equation 9 describes the determination of detrended consumption, $c_{t}$, according to the model with habit persistence where 26 percent of consumption is determined by rule-of-thumb consumers. Consumption depends on the current output gap, present values of future growth in output, the habit stock, $z_{t}$, and a measure of consumption relative to the habit stock, denoted by $q_{t}$, and the ex ante real long-term bond rate, $R_{t}$. The innovation to consumption is modeled as an $\operatorname{AR}(1)$ process. Non-consumption output is determined by its two own lags, the ex ante real bond rate (equation 10), and a serially uncorrelated innovation. Equation 11 is the identity equating the output gap to consumption non-consumption output. The ex ante real bond rate is determined by the expectations theory of the term structure (equation 17).

Of course, these three models comprise only a tiny subset of the entire universe of competing representations of the U.S. economy. Nevertheless, they do incorporate markedly different approaches toward controversial issues such as expectations formation and intrinsic persistence and, hence, can serve as a useful proving ground for various methods of identifying robust policy rules.

\section{Pitfalls of Using a Single Reference Model}

We now consider rules that are designed to yield robust performance in the neighborhood of a given reference model and analyze the extent to which such rules also work well in competing reference models. For this purpose, we assume that the policymaker's loss function $\mathcal{L}$ has the form:

$$
\mathcal{L}=\operatorname{Var}\left(\pi_{t}\right)+\lambda \operatorname{Var}\left(y_{t}\right)+\phi \operatorname{Var}\left(\Delta i_{t}\right)
$$

where $\operatorname{Var}(\cdot)$ denotes the unconditional variance of the indicated variable. The weights $\lambda \geq 0$ and $\phi \geq 0$ indicate the policymaker's preferences for reducing output variability and nominal interest 
rate variability relative to inflation variability.

The literature lacks consensus regarding the appropriate value of the output stability weight $(\lambda)$, even for a policymaker whose ultimate goal is to maximize household welfare. For example, Goodfriend and King (1997) and King and Wolman (1999) have argued that the central bank should focus solely on the objective of price stability, whereas King (1997) refers to a policymaker who ignores output stability $(\lambda=0)$ as an "inflation nutter." The relative weight on output volatility in the social welfare function can be derived analytically in a model with explicit microeconomic foundations, but this weight turns out to be highly sensitive to the particular specification of overlapping nominal contracts: random-duration "Calvo-style" contracts imply that $\lambda \approx 0.01$ (Woodford (2000)), whereas fixed-duration "Taylor-style" contracts imply that $\lambda \approx 1$ (Erceg and Levin (2002)).

The appropriate weight on nominal interest rate variability $(\phi)$ is also subject to ongoing debate. For example, Svensson (2003) criticizes the inclusion of this term in the policymaker's objective function, while Woodford (1999) shows that the optimal targeting rule is associated with a high degree of policy inertia even if $\phi=0$. On the other hand, Caplin and Leahy (1996) and Goodhart (1996) cite institutional reasons why policymakers may dislike frequent interest rate reversals, while Lowe and Ellis (1997) discuss the extent to which such preferences may reflect underlying concerns about financial market fragility. Finally, in the analysis of Rotemberg and Woodford (1997, 1999), interest rate volatility enters explicitly into the policymaker's objective function due to the zero bound on nominal interest rates.

Since the appropriate values of the objective function weights remain controversial, our analysis will be performed using a range of different values for each of the policy parameters. In particular, we will consider results using a grid of four different values for $\lambda(0,0.5,1$, and 2$)$ and three values of $\phi(0.1,0.5$, and 1.0$) .^{9}$

\subsection{Optimal Targeting Rules}

As noted above, the optimal targeting rule for a given reference model is invariant to the $d g p$ of the exogenous shock process, assuming that this $d g p$ is known to the policymaker at the time the rule is implemented. Thus, to the extent that a competing model can be accurately represented by a specific perturbation of the shock process of the reference model, then the optimal targeting rule for the reference model will also be optimal in the competing model. For this reason, Giannoni and Woodford (2002a) and Svensson and Woodford (2003a) advocate the use of optimal control as a method of obtaining a robust policy rule. On the other hand, Sargent (1999) has noted that

\footnotetext{
${ }^{9}$ We also tried smaller values for $\phi$, but the resulting optimal policies yielded extremely volatile short-term interest rates. For example, with $\phi=0.01$ and for the values of $\lambda$ that we consider, the unconditional variance of the quarterly change in the nominal interest rate ranges from 16 to 27 percent in NKB, 34 to 88 percent in FHP, and 35 to 80 percent in RS.
} 
the set of perturbations of the exogenous shock process only comprises a restrictive set of potential model misspecifications, because the perturbed shocks still feed through the system just as in the reference model. Thus, if the endogenous relationships of a competing model differ markedly from those of the reference model, then one might expect the optimal targeting rule for the reference model to perform quite poorly in the competing model.

We now investigate this issue using the three competing reference models described in Section 2. In particular, for each combination of objective function weights, we obtain the optimal targeting rule for a given model (referred to as the "rule-generating" model), and then implement this rule in a different reference model (referred to as the "true economy" model). As noted by Giannoni and Woodford (2002a), the optimal targeting rule can be expressed solely in terms of leads and lags of the target variables that enter the policymaker's objective function. Since these target variables $\left(\pi_{t}, y_{t}\right.$, and $\left.\Delta i_{t}\right)$ are defined in each of the competing reference models, the optimal targeting rule taken from one model can be implemented in another model even if other endogenous variables are not defined in both models. ${ }^{10}$

The results of this exercise are shown in Table 1. In each case, the performance of the rule is reported in terms of the policymaker loss function, $\mathcal{L}$, evaluated in the indicated model. ${ }^{11}$ (Details regarding the unconditional variances of the output gap, the inflation rate, and the change in the nominal short-term interest rate underlying the calculations of the losses reported in this table are reported in Table A1 of the Appendix.) To provide a measure of the relative performance of the policy rule in a particular model, we also report its relative loss, $\% \Delta \mathcal{L}$, equal to the percent difference between the loss under the specified policy rule and the first-best outcome obtainable in that model (that is, the outcome under the optimal targeting rule for that model). To interpret the economic significance of a particular magnitude of this metric, it is useful to consider historical variations in the value of $\% \Delta \mathcal{L}$. For example, setting the policy preference parameters $\lambda=1$ and $\phi=0.5$, we find that the value of $\mathcal{L}$ during the 1970 s was about 125 percent higher than during the 1990s. Thus, a rule generating $\% \Delta \mathcal{L}$ of 25 or even 50 percent might be viewed as yielding satisfactory performance, whereas a rule yielding $\% \Delta \mathcal{L}$ much greater than 100 percent would presumably be considered unacceptable.

Evidently, optimal targeting rules may yield very poor or even disastrous outcomes in competing reference models with markedly different endogenous relationships. For example, the upper panel indicates the performance from optimal targeting rules taken from the NKB model. By construction, the losses in the NKB model, reported in the third column, are the best obtainable, and

\footnotetext{
${ }^{10}$ We use the Finan and Tetlow (2001) algorithm to solve for the optimal policy and the Anderson and Moore (1985) "AIM" algorithm to solve for VAR representation of the stable solution for the rational expectations model. We compute the unconditional moments using the doubling algorithm described in Hansen and Sargent (1998).

${ }^{11}$ In certain models, a given change in the loss function can be expressed in terms of the corresponding certaintyequivalent change in steady-state household consumption. Unfortunately, such an approach is not feasible here, because the RS model does not have formal microeconomic foundations.
} 
therefore the relative losses, given in the sixth column, are identically zero. These policy rules, however, typically perform very poorly in the FHP model, with relative losses exceeding 3000 percent for $\lambda=0$, and relative losses of 60 to 120 percent for $\lambda \geq 0$. And these rules uniformly generate dynamic instability in the RS model; that is, $\% \Delta \mathcal{L}=\infty$ in every case. Similarly, optimal targeting rules taken from the FHP rule generate large relative losses in the NKB model and occasionally induce dynamic instability in the RS model. The only case in which optimal targeting rules provide a modicum of robust performance is when the rule is taken from the RS model for values of $\lambda>0$.

Identifying the source of this lack of robustness is a bit difficult, because each optimal targeting rule may have a somewhat complicated formulation in terms of leads and/or lags of the target variables. Thus, it is useful to pursue this issue further by considering the following class of simple 3-parameter rules:

$$
i_{t}=\rho i_{t-1}+(1-\rho) \bar{\pi}_{t}+\alpha \bar{\pi}_{t}+\beta y_{t}
$$

As noted above, we use $\bar{\pi}_{t}$ to denote the four-quarter average inflation rate. For each combination of $\lambda$ and $\phi$, we use numerical methods to determine the values of $\rho, \alpha$, and $\beta$ that minimize the policymaker's loss function in the rule-generating model. Then we implement this rule in each competing model and evaluate its performance relative to the optimal targeting rule for the true economy model. The results are reported in Table 2. (Corresponding details on the unconditional variances of inflation, the output gap, and the first-difference of the short-term interest rate are reported in Table A2 in the Appendix.)

When the rule-generating model is the same as the true economy model, the optimized 3parameter rule performs just about as well as the optimal targeting rule; that is, the relative loss $\% \Delta \mathcal{L}$ is less than 10 percent in nearly every case. Furthermore, these optimized 3-parameter rules exhibit essentially the same lack of robustness as the set of optimal targeting rules.

For these simple rules, the source of lack of robustness is fairly easy to identify. All of the rules optimized for the NKB model use values of $\rho$ above unity, and this super-inertial property is responsible for their dynamic instability in the RS model. The simple rules optimized for the FHP model use values of $\rho$ near unity, and even this degree of interest rate smoothing generally leads to dynamic instability in the RS model. Similar problems have previously been noted by Rudebusch and Svensson (1999), who report that dynamic instability results from the super-inertial rules obtained by Rotemberg and Woodford (1999) and from the first-difference rules obtained by Levin et al. (1999).

Finally, it should be noted that the rules optimized for the RS model involve little or no monetary policy inertia or "interest rate smoothing." To verify that this is the reason that these rules tend to perform poorly in the other two models, we now construct optimized rules with no interest rate smoothing; that is, for each rule-generating model and combination of objective function weights, we impose the restriction that $\rho=0$ and find the optimal values of $\alpha$ and $\beta$. The 
relative performance of these rules is reported in Table 3.

Imposing the restriction that $\rho=0$ has minimal effects on the relative performance of rules optimized for the RS model when this model is also the true economy model. By contrast, rules without policy inertia perform relatively poorly in the NKB and FHP models, even when the parameters $\alpha$ and $\beta$ are correctly optimized for the true economy model. In some cases, such rules lead to instability in the RS model owing to the instrument instability problem associated with excessively large reactions to inflation or output in backward-looking models.

\subsection{Robust Control Methods}

While the analysis thus far has highlighted the lack of robustness of optimal targeting rules, it should be emphasized that this outcome is caused primarily by the reliance on a single reference model in designing the policy rule. Thus, to the extent that many robust control methods follow a similar approach, these methods may be subject to the same pitfalls.

For example, Onatski and Stock (2002) use the RS model as a benchmark and analyze the robustness of simple rules when the behavioral equations of the model are subject to misspecification errors and the exogenous shock process is subject to unknown perturbations. Nevertheless, their analysis is restricted to the class of 2-parameter rules with no interest rate smoothing; as seen above, such rules yield acceptable performance in the RS model, but they perform quite poorly in the two competing reference models with forward-looking behavior.

Similarly, Giannoni (2001) considers the implications of parameter uncertainty using the NKB model as a benchmark and finds that robust rules involve even greater interest rate smoothing than the optimal targeting rule. ${ }^{12}$ Unfortunately, as we have seen above, such super-inertial rules uniformly generate dynamic instability in the RS model and perform quite poorly in the FHP model.

Ongoing research has been aimed at making robust control more robust to the types of model uncertainty highlighted here. A comprehensive investigation of other robust control methods is well beyond the scope of the current paper (see, for example, Tetlow and von zur Muehlen (2001), Hansen and Sargent (2002), and Onatski and Williams (2003)). Nevertheless, the results reported here suggest that simply designing a rule to be robust in the neighborhood of a given reference model does not ensure that the rule will perform robustly in competing reference models.

\footnotetext{
${ }^{12}$ Giannoni (2002) considers the same problem but focuses on 2-parameter rules with no interest rate smoothing; as seen above, however, imposing this restriction induces fairly large losses relative to the optimal targeting rule for the NKB model.
} 


\section{Fault Tolerance}

The previous results indicate that in some cases rules optimized to one model can perform reasonably well in other models, but in other cases, optimized rules yield disastrous outcomes in other models. For the remainder of the paper, we seek to find simple policy rules that perform well across the set of competing references models. A useful method to understand the results in the previous section and to identify rules that are robust to model uncertainty is to examine the "fault tolerance" of each model to deviations from the first-best optimal policy. ${ }^{13}$

Given policymaker preferences, we assess a model's fault tolerance by considering deviations of each policy rule parameter from its optimal value, holding the other parameters fixed at their optimal values. This approach differs from that taken in the robust control literature, which characterizes the potential losses under a given rule if the structural parameters or exogenous shock characteristics differ from those of the reference model. ${ }^{14}$ In particular, we refer to a model as possessing high fault tolerance with respect to a particular parameter if the loss function exhibits relatively little curvature with respect to sub-optimal deviations of that parameter. If the loss function is relatively insensitive to all three parameters of the policy rule, then we consider the model economy to be reasonably fault tolerant. Conversely, if the loss function exhibits strong curvature with respect to at least one policy parameter, then we conclude that the model economy is relatively fault intolerant.

We start by classifying the four types of fault tolerance or intolerance that can result in the competing reference model framework. For this purpose, we consider the simple illustrative example where the optimal policy is described by a single parameter, $\theta$, and there are two competing reference models, $A$ and $B$. For given policy preferences, the optimal policy in model $A$ is denoted by $\theta^{*}(A)$, and similarly for model $B$. In the first two cases, it is possible to derive a successful robust policy; in the third and the fourth, this goal is unobtainable.

In the first case, the models differ in their prescriptions for optimal policy, but the loss functions are nearly flat in the region of the optimal policies. The upper left panel of Figure 1 portrays such a case. The solid line shows the percent deviation from the first-best loss for model $A, \% \Delta \mathcal{L}$, as a function of $\theta$; this curve reaches its minimum of zero at $\theta^{*}(A)$. The dashed line shows the corresponding curve for model $B$. Note that the prescriptions of the models may differ dramatically, but, as long as the loss curves are relatively flat, this is not a barrier to finding a robust policy. With high degrees of fault tolerance, one can comfortably optimize policy based on one model, assured that the outcome in the other model is reasonably good. A "compromise" policy between

\footnotetext{
${ }^{13}$ Fault tolerance is a widely used concept in engineering, especially in the design of systems such as air- and spacecraft and computer hardware and software. Fault tolerance is defined to be "the ability of a system or component to continue normal operation despite the presence of ... faults" (IEEE Computer Society (1990)).

${ }^{14}$ For example, Onatski (2001) and Onatski and Stock (2002) evaluate the radius of catastrophic perturbations of a particular rule in terms of structural parameter deviations that generate dynamic instability or indeterminacy.
} 
the two optimal policies buys additional insurance at little cost to performance in either model. As shown in Levin et al. (1999), many estimated forward-looking macro models fall into this category, and the optimal policy rule from one model is close to optimal in other models.

In the second case, one model is highly intolerant to deviations from the optimal policy, but the losses in the other models are insensitive to deviations from optimality. Under these circumstances, the "squeaky wheel gets the grease," and the robust policy will be heavily weighted toward that demanded by the model(s) with the least tolerance. This case is illustrated in the upper right panel of the figure. In this example, the loss in model $A$ is highly sensitive to the value of $\theta$, but that in model $B$ is insensitive. As a result, the robust policy is closer to the optimal policy of model $A$ and performs well in both models.

In the third case, the models differ in their prescriptions for optimal policy, and the losses are highly sensitive to deviations of optimality. This case is shown in the lower left panel of the figure. Clearly, under these conditions it is impossible to design a robust policy that yields nearly optimal outcomes in all models. Robustness comes at a significant cost in terms of performance in any particular model. In extreme cases, the loss curves may not cross at all, implying that any given policy will be destabilizing in at least one model. This case is illustrated in the lower right panel.

The existence of a robust policy requires overlapping regions of high fault tolerance across the set of competing reference models. Otherwise, the set of models presents an unavoidable costly tradeoff between performance in any given model and robustness across models. Figure 2 plots out the fault tolerances for the three models for the case of $\lambda=0$ and $\phi=0.5$. Each curve traces the ratio of the loss to the first-best loss (denoted $\mathcal{L}^{*}$ ) as the specified policy is varied, holding the other two policy rule parameters fixed at their optimized values.

When the policymaker is unconcerned with output variability, the three models display a reasonable degree of fault tolerance to variations in parameters $\rho$ and $\alpha$, but are quite intolerant to variation in $\beta$, the coefficient on the output gap. The three models are tolerant of values of $\rho$ in the range of $1 / 4$ to $3 / 4$, but the $\mathrm{RS}$ model is intolerant to values of $\rho$ above $3 / 4$, when the problem of instrument instability begins to materialize. The models are tolerant to a wide range of values of $\alpha$. In contrast, the models demand very different values of $\beta$, with the forward-looking models performing best when $\beta$ is near zero and the RS model wanting a relatively large value. The key difference between the RS model and the other two models is that policy affects inflation only through its direct effect on output, while in the two forward-looking models, policy also affects inflation through the expectations channel. In those two models, it is sufficient to respond to inflation in order to stabilize inflation. Any further direct response to the output gap purchases lower output variability, which is of no value under these preferences, but comes at the cost of significantly greater inflation and interest rate variability.

The models exhibit much greater fault tolerance when the objective includes a nontrivial weight 
on output stabilization. Figure 3 plots out the fault tolerances for the three models for the case of $\lambda=1$ and $\phi=0.5$. The fault tolerance curves are relatively flat over wide ranges of policy rule parameters. The NKB model is especially tolerant of deviations from the optimal policy. Deviations from the optimal policy correspond to movements along the feasibility frontier. For example, an excessively high response to the inflation rate typically raises the variability of output and the interest rate, but this is partly offset by a decrease in inflation variability, lessening the net cost of deviating from the optimal policy. In essence, deviating from the optimal policy moves one along the feasibility frontier. The two binding restrictions from the three models are that $\rho$ not exceed 3/4 according to the RS model and that $\alpha$ not be too large according to the FHP model.

These results illustrate the potential value of fault tolerance analysis in either identifying the characteristics of a robust rule or revealing that a robust outcome is not likely to be attainable across the competing reference models. However, it is important to keep in mind that fault tolerance is evaluated by considering sub-optimal deviations of each parameter, holding the other parameters fixed; conceivably this approach might not be sufficient in some cases involving complex interactions of the policy rule parameters. Thus, before drawing any firm conclusions, it is essential to use quantitative methods to identify and evaluate the rule that yields optimal performance across the set of competing models; we do so in the following section.

\section{Robustness to Competing Reference Models}

Now we identify the optimal simple rule that yields robust performance within the set of competing reference models; that is, we find the rule that minimizes a specific function of the loss generated in each of the individual models. This approach has been advocated by Chow (1973), McCallum (1988), and Taylor (1999) and has been implemented in forward-looking models by Levin et al. (1999) and Levin et al. (2003).

We consider two methods of aggregating the losses in the reference models. The first takes a Bayesian perspective and weights the outcomes from the different models according to priors over the models. The second approach does not place weights on the models, but instead the policymaker seeks to minimize the maximum loss across the models. For a given objective function and policy preference parameters, $\lambda$ and $\phi$, we find the values of the policy parameters that minimize the specified objective.

\subsection{The Bayesian Approach}

The Bayesian objective function, denoted by $\mathcal{L}^{B}$, is given by

$$
\mathcal{L}^{B}=\omega_{N K B} \mathcal{L}_{N K B}+\omega_{F H P} \mathcal{L}_{F H P}+\omega_{R S} \mathcal{L}_{R S},
$$


where $\omega_{X}$ denotes the weight applied to model $X$. The weights sum to unity. In the following, we consider various combinations of the weights over the the three models.

Table 4 reports the outcomes for the case of equal weights on the three models. (Details on the unconditional variances of inflation, the output gap, and the first-difference of the short-term interest rate are reported in Table A3 in the Appendix.) The third through fifth columns report the optimized values of the three coefficients of the Bayesian robust policy rule. The next three columns report the resulting losses in the three models. The ninth through eleventh columns report the percent difference between the loss in the specified model under the robust policy rule relative to that under the first-best optimal control policy. For example, in the case $\lambda=0$ and $\phi=0.1$, reported in the first row of the table, the robust policy yields a loss that is 173 percent higher than the first-best policy in the NKB model. ${ }^{15}$ The final column shows the percent difference between the weighted losses across the three models under the robust rule relative to the weighted outcomes under the first-best policy in each model.

For a policymaker who is concerned only with stabilizing inflation and interest $\operatorname{rates}(\lambda=0)$, robustness to model uncertainty comes at the cost of a significant loss in performance relative to the first-best in all three models. As seen in the table, for these preferences the average loss is between about 60 to 75 percent above the first-best outcome. Evidently, in this case, the differences in the model structures are sufficiently large that it is not possible to come up with a single monetary policy rule that performs very well in all three models. Note that this conclusion does not depend on the particular weight on interest rate variability, but does depend on the weights given to the three models, as discussed below.

In contrast to the case of $\lambda=0$, if the policymaker values both inflation and output stabilization, the robust policies nearly achieve the first-best in all three models. For example, when $\lambda=1 / 2$, the average loss is at most 15 percent above the first-best, and is no more than 21 percent worse than the first-best in any given model. For higher values of $\lambda$, the results are similar, with the average loss no more than 24 percent higher than first best. Clearly, when the policymaker seeks to stabilize output and inflation, choosing the policy parameters to minimize the average loss function across the three models does not generate large stabilization costs relative to fine-tuning these parameters to a particular model. Given the already excellent performance of the robust rule with equal weights, the same rule would be nearly optimal even for a policymaker with very different (non-flat) prior beliefs about the accuracy of the three models. These results are not sensitive to the weight on interest rate variability in the objective function.

Using more than three parameters in the policy rule does not appreciably improve performance.

\footnotetext{
${ }^{15}$ Note that even with equal weighting of the outcomes, the percent difference between the loss under the Bayesian robust rule and the first-best is in each case greatest for the NKB model. This reflects the lower level of aggregate variability in the NKB model for the Bayesian robust rules. The high percent deviation from first-best corresponds to a relatively small absolute difference from optimal, and it is the level of the loss that affects the choice of the rule parameters, not the percent deviation from first-best.
} 
Table 5 reports the relative performance of 6-parameter Bayesian robust rules, in which the policy rule is allowed to respond additionally to the second lag of the interest rate, the current one-quarter inflation rate, and the first lag of the output gap. In the case of $\lambda=0$, the 6-parameter Bayesian robust rule does moderately better than the 3 -parameter variant, but for $\lambda>0$, the improvement is trivial. The reason that adding more variables yields little benefit to the Bayesian robust rules is that these rules by their nature are optimized to the "average" behavior of the various benchmark models. In any given model, fine-tuning to the particular dynamic structure of the model can be useful, but the models tend to differ in the specifics. ${ }^{16}$ Consequently, the Bayesian robust policy downplays such fine-tuning, and the extra parameters are of little use.

Eliminating the response to the lagged interest rate, however, can cause a noticeable deterioration in performance of the Bayesian robust policy rules. Table 6 reports the relative performance of 2-parameter Bayesian robust rules for which $\rho$ has been constrained to zero as in the original Taylor rule. This restriction has little effect on the performance of the Bayesian robust rule when $\lambda=$ or $\phi=0.1$. But, when the policymaker places substantial weight on the stabilization of output and interest rates, along with inflation, this constraint on the degree of policy inertia carries significant costs. In forward-looking models where output depends on a long-term interest rate, policy inertia reduces the variability of short-term interest rates necessary to achieve a given movement in long-term rates, as discussed in Levin et al. (1999) Williams (2003). For example, with $\lambda=1$, the constraint increases the Bayesian loss by 10 percent for $\phi=0.5$ and by 20 percent for $\phi=1$. Given these results, we focus on 3-parameter policy rules of the form given by equation 20 .

\subsection{The Minimax Approach}

When the policymaker seeks to minimize the maximum loss across the three models, the objective function $\mathcal{L}^{M}$ is given by

$$
\mathcal{L}^{M}=\max \left\{\mathcal{L}_{N K B}, \mathcal{L}_{F H P}, \mathcal{L}_{R S}\right\}
$$

Table 7 reports the results obtained under this objective function. In all cases, the minimax robust policy equates the loss under the FHP and RS models; the low level of variability in the NKB model makes it irrelevant for the minimax analysis. Given the high baseline level of the loss in the FHP model, the minimax policy effectively weights that model very heavily and, as a result, performance in the RS model, and to a lesser extent, the NKB model, suffers. Indeed, the policy rule parameters are close to those implied by the FHP model alone. This sensitivity to the baseline loss of each model is a problematic feature of the minimax approach (see also Sims (2001) for further comments on Bayesian and minimax criteria).

\footnotetext{
${ }^{16}$ The 3-parameter instrument rule yields losses no more than 7 percent, 14 percent, and 3 percent above the optimal control policy in the NKB, FHP, and RS models, respectively.
} 


\section{Robustness to other Models}

In the preceding section we identified monetary policy rules that were optimized allowing for uncertainty regarding the three reference models. We now evaluate the performance of the resulting rules in a number of alternative models. Four of these models were considered in the robustness analysis of Levin et al. (1999, 2003): the Fuhrer-Moore (FM) model, the macroeconometric model of the Federal Reserve Board (FRB), the Monetary Studies Research (MSR) model (also developed at the Board of Governors), and John Taylor's multicountry model (TMCM). ${ }^{17}$ We also include the model of Rudebusch (2002), henceforth denoted as the R02 model, that is similar to the RS model but incorporates some forward-looking elements. Each of these five macroeconometric models incorporates some type of nominal inertia and some degree of forward-looking behavior, and monetary policy primarily affects economic activity and inflation through the interest rate channel. On the other hand, the five models do represent a fairly wide range of different approaches to model specification and estimation. Thus, it is useful to consider whether the rules obtained in the previous analysis also perform well in these alternative models; in effect, this exercise roughly corresponds to an out-of-sample forecasting test.

Table ?? reports the results of this exercise, which are largely consistent with our earlier results. In particular, when the policymaker places substantial weight on output stability $(\lambda>0)$, we find that the rules designed to perform well in the three competing models also yield reasonable (although not stellar) performance in each of these other models. And as in the previous section, obtaining a robust outcome is not feasible when the policymaker is oriented towards strict inflation targeting $(\lambda=0)$.

\section{Conclusion}

Although an extensive literature has considered the problem of obtaining a policy rule that is robust to modifications of a specific reference model, our analysis indicates that the robustness of such rules may be somewhat illusory, because policymakers actually face a much greater degree of model uncertainty. Thus, a more promising approach is to consider a range of distinct reference models and to identify rules that provide robust performance across these models. Our results also highlight the advantages of considering the "fault tolerance" of each competing reference model as a means of characterizing and interpreting the conditions under which a robust policy outcome is attainable.

The main finding from our model-based analysis is positive: it is possible to find policy rules

\footnotetext{
${ }^{17}$ The FM model was formulated by Fuhrer and Moore (1995), with updated parameter estimates given in Fuhrer (1997a). The FRB model is described in Brayton, Mauskopf, Reifschneider, Tinsley and Williams (1997), while Orphanides and Wieland (1998) document the properties of the MSR model, and Taylor (1993b) provides extensive documentation of TMCM.
} 
that perform very well in a wide range of macro models as long as the policymaker cares about both inflation and output variability. Or, put differently, the members of a policymaking committee who share similar preferences for stabilizing fluctuations in inflation, output, and interest rates, but who have quite different views of the dynamics behavior of the economy, can relatively easily come to a mutually acceptable compromise over the design of monetary policy. Only in the case where policymakers are indifferent to fluctuations in output do the models lack fault tolerance, and, as a result finding a mutually agreeable policy becomes problematic.

In future research, it will be useful to extend this approach in several directions. Throughout our analysis, we have assumed that the policymaker observes all macroeconomic variables, including latent variables such as the natural rates of output, unemployment, and interest, without error. But, as Staiger, Stock and Watson (1997), Orphanides and van Norden (2002), Laubach and Williams (2003), and others have documented, natural rates tend to be poorly measured, especially in real time. A natural extension of this paper would incorporate natural rate mismeasurement into the analysis and derive policy rules that are robust to both model and natural rate uncertainties. ${ }^{18}$ We have also assumed that the parameters of the reference models are known with certainty. It is relatively straightforward to extend this approach to allow for parameter uncertainty in computing the losses in each model either using Bayesian or robust control approaches. ${ }^{19}$

We have also assumed that the policymakers' objective function, in terms of the variability of output, inflation, and interest rates, is known and invariant across the models. In the context of models with well-specified household optimization problems, the welfare maximization problem can be approximated by the loss used in this paper. The relative weights in the loss function, however, depend on the structure and parameters of the particular model. Levin and Williams (2003) examine the links between parameter uncertainty and uncertainty regarding the weights and structure of the objective function implied by micro-founded models, and the implications of these cross-equation restrictions for monetary policy.

Finally, we have assumed that policymakers never update their beliefs about the relevance of the competing reference models. An open question is the design of robust policy when the policymaker gradually obtains additional knowledge about the true structure of the economy.

\footnotetext{
${ }^{18}$ Smets (1999), Orphanides, Porter, Reifschneider, Tetlow and Finan (2000), McCallum (2001 (Papers and Procedings)), Rudebusch (2002), Nelson and Nikolov (2002), Orphanides and Williams (2002), and others have analyzed the role of natural rate uncertainty in the design and performance of monetary policy rules. See also Meyer, Swanson and Wieland (2001) and Svensson and Woodford (2003b).

${ }^{19}$ Rudebusch (2001), Giannoni (2002), Onatski and Stock (2002), and Onatski and Williams (2003) examine the design of policy under parameter uncertainty.
} 
Table 1: Performance of Optimal Targeting Rules in Competing Reference Models

\begin{tabular}{|c|c|c|c|c|c|c|c|}
\hline \multicolumn{2}{|c|}{$\begin{array}{l}\text { Policymaker } \\
\text { Preferences }^{1}\end{array}$} & \multicolumn{3}{|c|}{$\underset{\text { evaluated in }}{\mathcal{L}}$} & \multicolumn{3}{|c|}{$\begin{array}{c}\% \Delta \mathcal{L} \\
\text { evaluated in }\end{array}$} \\
\hline$\lambda$ & $\phi$ & NKB & FHP & RS & NKB & FHP & $\mathrm{RS}$ \\
\hline \multicolumn{8}{|c|}{ Optimal policy for $N K B$} \\
\hline \multirow{3}{*}{0.0} & 0.1 & 1.4 & 95.3 & $\infty$ & 0 & 3024 & $\infty$ \\
\hline & 0.5 & 1.9 & 149.7 & $\infty$ & 0 & 3718 & $\infty$ \\
\hline & 1.0 & 2.1 & 178.8 & $\infty$ & 0 & 3989 & $\infty$ \\
\hline \multirow{3}{*}{0.5} & 0.1 & 5.8 & 22.1 & $\infty$ & 0 & 62 & $\infty$ \\
\hline & 0.5 & 8.2 & 28.9 & $\infty$ & 0 & 92 & $\infty$ \\
\hline & 1.0 & 9.7 & 36.1 & $\infty$ & 0 & 127 & $\infty$ \\
\hline \multirow{3}{*}{1.0} & 0.1 & 6.1 & 27.4 & $\infty$ & 0 & 60 & $\infty$ \\
\hline & 0.5 & 9.6 & 36.0 & $\infty$ & 0 & 84 & $\infty$ \\
\hline & 1.0 & 12.1 & 45.0 & $\infty$ & 0 & 116 & $\infty$ \\
\hline \multirow{3}{*}{2.0} & 0.1 & 6.4 & 35.4 & $\infty$ & 0 & 63 & $\infty$ \\
\hline & 0.5 & 11.0 & 46.9 & $\infty$ & 0 & 83 & $\infty$ \\
\hline & 1.0 & 14.6 & 58.1 & $\infty$ & 0 & 109 & $\infty$ \\
\hline
\end{tabular}

Optimal policy for FHP

\begin{tabular}{rrrrrrrr}
\hline \multirow{2}{*}{0.0} & 0.1 & 3.9 & 3.1 & $\infty$ & 173 & 0 & $\infty$ \\
& 0.5 & 4.4 & 3.9 & $\infty$ & 130 & 0 & $\infty$ \\
& 1.0 & 4.6 & 4.4 & $\infty$ & 120 & 0 & $\infty$ \\
\hline \multirow{3}{*}{0.5} & 0.1 & 10.9 & 13.6 & 13.9 & 89 & 0 & 94 \\
& 0.5 & 17.1 & 15.0 & 12.3 & 108 & 0 & 41 \\
& 1.0 & 20.2 & 15.9 & 12.3 & 102 & 0 & 27 \\
\hline \multirow{3}{*}{1.0} & 0.1 & 12.8 & 17.2 & 39.7 & 108 & 0 & 318 \\
& 0.5 & 23.5 & 19.5 & 19.0 & 144 & 0 & 68 \\
& 1.0 & 29.5 & 20.9 & 22.8 & 145 & 0 & 84 \\
\hline \multirow{3}{*}{2.0} & 0.1 & 14.4 & 21.7 & $\infty$ & 124 & 0 & $\infty$ \\
& 0.5 & 31.8 & 25.6 & 36.3 & 190 & 0 & 130 \\
& 1.0 & 42.0 & 27.9 & 30.9 & 187 & 0 & 80 \\
\hline
\end{tabular}

Optimal policy for $R S$

\begin{tabular}{rrrrrrrr}
\hline \multirow{3}{*}{0.0} & 0.1 & 4.6 & 7.5 & 4.0 & 219 & 146 & 0 \\
& 0.5 & 6.8 & 9.0 & 5.5 & 254 & 128 & 0 \\
& 1.0 & 8.5 & 9.9 & 6.4 & 306 & 126 & 0 \\
\hline \multirow{3}{*}{0.5} & 0.1 & 7.4 & 17.2 & 7.2 & 28 & 26 & 0 \\
& 0.5 & 11.5 & 18.7 & 8.7 & 39 & 25 & 0 \\
& 1.0 & 14.5 & 19.7 & 9.7 & 50 & 24 & 0 \\
\hline \multirow{3}{*}{1.0} & 0.1 & 8.9 & 23.5 & 9.5 & 44 & 37 & 0 \\
& 0.5 & 14.3 & 25.8 & 11.3 & 49 & 32 & 0 \\
& 1.0 & 18.6 & 27.2 & 12.4 & 54 & 30 & 0 \\
\hline \multirow{3}{*}{2.0} & 0.1 & 10.7 & 33.1 & 13.4 & 68 & 52 & 0 \\
& 0.5 & 18.3 & 37.1 & 15.8 & 67 & 45 & 0 \\
& 1.0 & 24.3 & 39.4 & 17.1 & 66 & 41 & 0 \\
\hline
\end{tabular}

Notes: 1 . The policymaker loss function is given by: $\mathcal{L}=\operatorname{Var}(\pi)+\lambda \operatorname{Var}(y)+\phi \operatorname{Var}(\Delta i)$. 
Table 2: Robustness of Optimized Three-Parameter Policy Rules

\begin{tabular}{|c|c|c|c|c|c|c|c|c|c|c|}
\hline \multicolumn{2}{|c|}{$\begin{array}{l}\text { Policymaker } \\
\text { Preferences }^{1}\end{array}$} & \multicolumn{3}{|c|}{$\begin{array}{l}\text { Policy Rule } \\
\text { Coefficients }^{2}\end{array}$} & \multicolumn{3}{|c|}{$\underset{\text { evaluated in }}{\mathcal{L}}$} & \multicolumn{3}{|c|}{$\begin{array}{c}\% \Delta \mathcal{L} \\
\text { evaluated in }\end{array}$} \\
\hline$\lambda$ & $\phi$ & $\rho$ & $\alpha$ & $\beta$ & NKB & FHP & $\mathrm{RS}$ & NKB & FHP & $\mathrm{RS}$ \\
\hline \multicolumn{11}{|c|}{ Optimized policy for NKB } \\
\hline \multirow{3}{*}{0.0} & 0.1 & 1.5 & 6.9 & -.0 & 1.6 & 21.6 & $\infty$ & 7 & 608 & $\infty$ \\
\hline & 0.5 & 1.5 & 2.7 & .0 & 2.0 & 36.5 & $\infty$ & 6 & 832 & $\infty$ \\
\hline & 1.0 & 1.5 & 1.9 & .0 & 2.2 & 44.3 & $\infty$ & 5 & 912 & $\infty$ \\
\hline \multirow{3}{*}{0.5} & 0.1 & 1.6 & 4.6 & 5.5 & 6.1 & 18.0 & $\infty$ & 5 & 32 & $\infty$ \\
\hline & 0.5 & 1.5 & 1.7 & 1.4 & 8.6 & 23.0 & $\infty$ & 5 & 53 & $\infty$ \\
\hline & 1.0 & 1.5 & 1.2 & .8 & 10.2 & 29.1 & $\infty$ & 5 & 84 & $\infty$ \\
\hline \multirow{3}{*}{1.0} & 0.1 & 1.6 & 4.5 & 10.4 & 6.4 & 24.7 & $\infty$ & 4 & 44 & $\infty$ \\
\hline & 0.5 & 1.5 & 1.5 & 2.5 & 10.0 & 28.8 & $\infty$ & 4 & 48 & $\infty$ \\
\hline & 1.0 & 1.5 & 1.1 & 1.4 & 12.6 & 34.6 & $\infty$ & 5 & 66 & $\infty$ \\
\hline \multirow{3}{*}{2.0} & 0.1 & 1.6 & 4.4 & 20.1 & 6.6 & 36.1 & $\infty$ & 3 & 66 & $\infty$ \\
\hline & 0.5 & 1.5 & 1.5 & 4.5 & 11.3 & 39.5 & $\infty$ & 4 & 54 & $\infty$ \\
\hline & 1.0 & 1.5 & 1.1 & 2.5 & 15.3 & 44.7 & $\infty$ & 4 & 60 & $\infty$ \\
\hline
\end{tabular}

Optimized policy for FHP

\begin{tabular}{rrrrrrrrrrr}
\hline \multirow{3}{*}{0.0} & 0.1 & 1.0 & 1.8 & .1 & 2.3 & 3.1 & $\infty$ & 60 & 3 & $\infty$ \\
& 0.5 & 1.0 & .7 & .0 & 2.8 & 4.0 & $\infty$ & 45 & 3 & $\infty$ \\
& 1.0 & 1.0 & .5 & .0 & 3.0 & 4.5 & $\infty$ & 41 & 3 & $\infty$ \\
\hline \multirow{3}{*}{0.5} & 0.1 & .9 & 1.2 & 1.2 & 6.9 & 15.2 & $\infty$ & 20 & 12 & $\infty$ \\
& 0.5 & .9 & .5 & .5 & 10.0 & 16.3 & 26.9 & 21 & 9 & 207 \\
& 1.0 & .9 & .3 & .3 & 11.7 & 17.0 & 22.6 & 21 & 7 & 132 \\
\hline \multirow{3}{*}{1.0} & 0.1 & .9 & 1.3 & 2.0 & 7.5 & 19.4 & $\infty$ & 21 & 13 & $\infty$ \\
& 0.5 & .9 & .5 & .8 & 12.0 & 21.4 & 77.3 & 24 & 10 & 581 \\
& 1.0 & .9 & .4 & .5 & 14.9 & 22.6 & 26.1 & 24 & 8 & 110 \\
\hline \multirow{3}{*}{2.0} & 0.1 & .9 & 1.4 & 3.1 & 7.9 & 24.7 & $\infty$ & 24 & 14 & $\infty$ \\
& 0.5 & .9 & .6 & 1.3 & 14.1 & 28.3 & $\infty$ & 29 & 11 & $\infty$ \\
& 1.0 & .9 & .4 & .9 & 18.7 & 30.4 & 93.3 & 27 & 9 & 445 \\
\hline
\end{tabular}

Optimized policy for $R S$

\begin{tabular}{rrrrrrrrrrr}
\hline \multirow{4}{*}{0.0} & 0.1 & .1 & 3.6 & 1.7 & 4.9 & 7.7 & 4.1 & 236 & 151 & 2 \\
& 0.5 & .4 & 1.7 & .9 & 7.1 & 9.1 & 5.6 & 270 & 131 & 2 \\
& 1.0 & .5 & 1.2 & .7 & 8.7 & 10.0 & 6.6 & 314 & 128 & 2 \\
\hline \multirow{3}{*}{0.5} & 0.1 & -.1 & 3.0 & 2.5 & 7.3 & 17.1 & 7.3 & 27 & 25 & 2 \\
& 0.5 & .2 & 1.6 & 1.3 & 11.6 & 18.9 & 8.9 & 41 & 25 & 2 \\
& 1.0 & .3 & 1.1 & .9 & 14.7 & 19.9 & 9.9 & 52 & 26 & 2 \\
\hline \multirow{3}{*}{1.0} & 0.1 & -.2 & 2.8 & 2.8 & 8.7 & 22.9 & 9.7 & 41 & 34 & 2 \\
& 0.5 & .1 & 1.5 & 1.5 & 14.4 & 25.8 & 11.5 & 50 & 32 & 1 \\
& 1.0 & .3 & 1.1 & 1.1 & 18.7 & 27.3 & 12.6 & 55 & 31 & 1 \\
\hline \multirow{3}{*}{2.0} & 0.1 & -.3 & 2.5 & 3.3 & 10.5 & 31.8 & 13.8 & 64 & 46 & 3 \\
& 0.5 & .0 & 1.4 & 1.8 & 18.2 & 36.6 & 16.0 & 66 & 43 & 1 \\
& 1.0 & .2 & 1.1 & 1.3 & 24.4 & 39.3 & 17.3 & 66 & 41 & 1 \\
\hline
\end{tabular}

Notes: 1 . The policymaker loss function is given by: $\mathcal{L}=\operatorname{Var}(\pi)+\lambda \operatorname{Var}(y)+\phi \operatorname{Var}(\Delta i)$. 2. The policy rule is given by: $i_{t}=\rho i_{t-1}+(1-1 \rho) \bar{\pi}_{t}+\alpha \bar{\pi}_{t}+\beta y_{t}$. 
Table 3: Robustness of Optimized Simple Rules with no Policy Inertia

Policymaker Policy Rule

Preferences $^{1} \quad$ Coefficients $^{2}$

$\mathcal{L}$

evaluated in

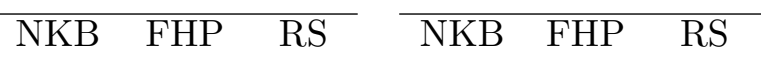

Optimized policy for NKB

\begin{tabular}{rrrrrrrrrrr}
\hline \multirow{2}{*}{0.0} & 0.1 & 0 & 4.3 & -.0 & 2.4 & 4.0 & $\infty$ & 68 & 32 & $\infty$ \\
& 0.5 & 0 & 1.2 & .0 & 3.6 & 5.9 & 10.2 & 88 & 49 & 212 \\
& 1.0 & 0 & .4 & -.0 & 4.2 & 7.6 & 16.0 & 100 & 73 & 321 \\
\hline \multirow{3}{*}{0.5} & 0.1 & 0 & 5.8 & 9.8 & 6.5 & 24.5 & $\infty$ & 12 & 79 & $\infty$ \\
& 0.5 & 0 & .7 & 1.9 & 12.4 & 24.4 & 14.4 & 50 & 62 & 191 \\
& 1.0 & 0 & .3 & .9 & 17.7 & 25.0 & 24.1 & 83 & 58 & 341 \\
\hline \multirow{3}{*}{1.0} & 0.1 & 0 & 6.4 & 20.6 & 6.7 & 39.8 & $\infty$ & 9 & 132 & $\infty$ \\
& 0.5 & 0 & .6 & 4.1 & 13.2 & 42.6 & 29.6 & 37 & 118 & 375 \\
& 1.0 & 0 & .1 & 2.0 & 20.2 & 53.9 & 81.7 & 67 & 158 & 1102 \\
\hline \multirow{3}{*}{2.0} & 0.1 & 0 & 6.7 & 42.1 & 6.8 & 61.6 & $\infty$ & 6 & 183 & $\infty$ \\
& 0.5 & 0 & .6 & 8.4 & 13.6 & 77.6 & $\infty$ & 24 & 203 & $\infty$ \\
& 1.0 & 0 & .0 & 4.2 & 21.5 & 191.4 & $\infty$ & 47 & 587 & $\infty$ \\
\hline
\end{tabular}

Optimized policy for FHP

\begin{tabular}{rrrrrrrrrrr}
\hline \multirow{2}{*}{0.0} & 0.1 & 0 & 4.2 & .0 & 2.4 & 4.0 & $\infty$ & 69 & 32 & $\infty$ \\
& 0.5 & 0 & 1.8 & .0 & 3.7 & 5.7 & 11.2 & 92 & 44 & 245 \\
& 1.0 & 0 & 1.2 & .0 & 4.4 & 6.7 & 10.6 & 111 & 53 & 181 \\
\hline \multirow{3}{*}{0.5} & 0.1 & 0 & 2.2 & 2.1 & 7.3 & 16.7 & 7.5 & 27 & 23 & 82 \\
& 0.5 & 0 & 1.1 & .9 & 13.4 & 19.1 & 10.0 & 63 & 27 & 103 \\
& 1.0 & 0 & .8 & .7 & 18.2 & 20.5 & 12.0 & 88 & 29 & 120 \\
\hline \multirow{3}{*}{1.0} & 0.1 & 0 & 2.1 & 3.1 & 7.8 & 21.6 & 10.2 & 27 & 26 & 91 \\
& 0.5 & 0 & 1.0 & 1.4 & 15.3 & 25.8 & 12.6 & 54 & 32 & 102 \\
& 1.0 & 0 & .7 & 1.0 & 22.0 & 28.2 & 14.7 & 74 & 35 & 116 \\
\hline \multirow{3}{*}{2.0} & 0.1 & 0 & 2.0 & 4.4 & 8.1 & 28.0 & 16.1 & 27 & 29 & 121 \\
& 0.5 & 0 & .9 & 2.0 & 16.9 & 35.1 & 17.3 & 53 & 37 & 106 \\
& 1.0 & 0 & .7 & 1.4 & 25.5 & 39.2 & 19.6 & 69 & 41 & 116 \\
\hline
\end{tabular}

Optimized policy for $R S$

\begin{tabular}{rrrrrrrrrrr}
\hline \multirow{2}{*}{0.0} & 0.1 & 0 & 4.1 & 1.9 & 5.0 & 7.8 & 2.5 & 244 & 154 & 3 \\
& 0.5 & 0 & 2.4 & 1.1 & 8.8 & 9.6 & 3.4 & 359 & 145 & 5 \\
& 1.0 & 0 & 1.9 & .9 & 12.5 & 10.9 & 4.0 & 499 & 149 & 7 \\
\hline \multirow{3}{*}{0.5} & 0.1 & 0 & 2.8 & 2.3 & 7.3 & 16.8 & 4.2 & 25 & 23 & 2 \\
& 0.5 & 0 & 1.9 & 1.4 & 12.8 & 19.9 & 5.1 & 56 & 32 & 2 \\
& 1.0 & 0 & 1.6 & 1.1 & 18.3 & 21.9 & 5.6 & 88 & 38 & 4 \\
\hline \multirow{3}{*}{1.0} & 0.1 & 0 & 2.4 & 2.5 & 8.5 & 22.3 & 5.5 & 38 & 30 & 3 \\
& 0.5 & 0 & 1.7 & 1.6 & 15.2 & 26.7 & 6.3 & 58 & 37 & 2 \\
& 1.0 & 0 & 1.4 & 1.3 & 21.7 & 29.7 & 7.0 & 80 & 42 & 3 \\
\hline \multirow{3}{*}{2.0} & 0.1 & 0 & 2.0 & 2.7 & 10.4 & 30.4 & 7.6 & 62 & 40 & 4 \\
& 0.5 & 0 & 1.5 & 1.8 & 18.4 & 37.0 & 8.5 & 68 & 45 & 1 \\
& 1.0 & 0 & 1.2 & 1.5 & 26.3 & 41.5 & 9.2 & 80 & 49 & 2 \\
\hline
\end{tabular}

Notes: See Table 2. 
Table 4: Performance of Bayesian Robust 3-Parameter Rules

\begin{tabular}{|c|c|c|c|c|c|c|c|c|c|c|c|}
\hline \multicolumn{2}{|c|}{$\begin{array}{c}\text { Central Bank } \\
\text { Preferences }\end{array}$} & \multicolumn{3}{|c|}{$\begin{array}{l}\text { Policy Rule } \\
\text { Coefficients }\end{array}$} & \multicolumn{3}{|c|}{$\begin{array}{c}\mathcal{L} \\
\text { evaluated in }\end{array}$} & \multicolumn{3}{|c|}{$\begin{array}{c}\% \Delta \mathcal{L} \\
\text { evaluated in }\end{array}$} & \multirow[t]{2}{*}{$\% \Delta \mathcal{L}^{B}$} \\
\hline$\lambda$ & $\phi$ & $\rho$ & $\alpha$ & $\beta$ & NKB & FHP & $\mathrm{RS}$ & NKB & FHP & $\mathrm{RS}$ & \\
\hline \multirow{3}{*}{0.0} & 0.1 & .2 & 2.8 & .8 & 4.0 & 5.7 & 5.2 & 173 & 88 & 29 & 75 \\
\hline & 0.5 & .4 & 1.1 & .3 & 4.3 & 6.3 & 7.5 & 127 & 61 & 38 & 61 \\
\hline & 1.0 & .5 & .8 & .2 & 4.5 & 6.7 & 9.0 & 115 & 54 & 40 & 57 \\
\hline \multirow{3}{*}{0.5} & 0.1 & .4 & 1.9 & 1.9 & 6.8 & 15.9 & 7.7 & 18 & 17 & 8 & 15 \\
\hline & 0.5 & .4 & .7 & .8 & 9.9 & 17.0 & 9.6 & 20 & 13 & 10 & 14 \\
\hline & 1.0 & .7 & .5 & .5 & 11.7 & 17.6 & 10.9 & 21 & 11 & 12 & 14 \\
\hline \multirow{3}{*}{1.0} & 0.1 & .3 & 1.8 & 2.5 & 7.7 & 20.7 & 10.5 & 25 & 21 & 11 & 19 \\
\hline & 0.5 & .6 & .8 & 1.1 & 12.1 & 22.5 & 12.7 & 26 & 15 & 12 & 17 \\
\hline & 1.0 & .7 & .5 & .7 & 15.1 & 23.5 & 14.0 & 26 & 12 & 13 & 16 \\
\hline \multirow{3}{*}{2.0} & 0.1 & .1 & 1.7 & 3.4 & 8.6 & 27.5 & 15.3 & 35 & 27 & 14 & 24 \\
\hline & 0.5 & .5 & .8 & 1.6 & 14.7 & 30.6 & 18.1 & 34 & 20 & 15 & 21 \\
\hline & 1.0 & .6 & .5 & 1.1 & 19.4 & 32.3 & 19.8 & 32 & 16 & 16 & 20 \\
\hline
\end{tabular}

Notes: See Table 2. For each pair of values of the preference parameters $\lambda$ and $\phi$, the corresponding row of this table indicates the policy rule coefficients and stabilization performance of the optimized 3 -parameter policy rule that minimizes the Bayesian loss function with equal weights. $\% \Delta \mathcal{L}^{B}$ denotes the percent deviation of the weighted loss function under the specified robust rule relative to weighted losses resulting from the first-best policy being followed in each model. 
Table 5: Performance of Bayesian Robust Rules with Additional Parameters

\begin{tabular}{|c|c|c|c|c|c|}
\hline \multicolumn{2}{|c|}{$\begin{array}{l}\text { Central Bank } \\
\text { Preferences }{ }^{1}\end{array}$} & \multicolumn{3}{|c|}{$\begin{array}{c}\% \Delta \mathcal{L} \\
\text { evaluated in }\end{array}$} & \multirow[t]{2}{*}{$\% \Delta \mathcal{L}^{B}$} \\
\hline$\lambda$ & $\phi$ & NKB & FHP & $\mathrm{RS}$ & \\
\hline \multirow{3}{*}{0.0} & 0.1 & 122 & 82 & 27 & 63 \\
\hline & 0.5 & 98 & 65 & 26 & 52 \\
\hline & 1.0 & 94 & 62 & 26 & 49 \\
\hline \multirow{3}{*}{0.5} & 0.1 & 18 & 17 & 7 & 15 \\
\hline & 0.5 & 18 & 14 & 9 & 14 \\
\hline & 1.0 & 18 & 12 & 10 & 13 \\
\hline \multirow{3}{*}{1.0} & 0.1 & 24 & 21 & 10 & 19 \\
\hline & 0.5 & 25 & 16 & 11 & 17 \\
\hline & 1.0 & 24 & 13 & 12 & 16 \\
\hline \multirow{3}{*}{2.0} & 0.1 & 23 & 15 & 20 & 18 \\
\hline & 0.5 & 33 & 19 & 15 & 21 \\
\hline & 1.0 & 31 & 15 & 14 & 19 \\
\hline
\end{tabular}

Notes: For each pair of values of the preference parameters $\lambda$ and $\phi$, the corresponding row of this table indicates the policy rule coefficients and stabilization performance of the optimized 6 -parameter policy rule that minimizes the Bayesian loss function with equal weights. $\% \Delta \mathcal{L}^{B}$ denotes the percent deviation of the weighted loss function under the specified robust rule relative to weighted losses resulting from the first-best policy being followed in each model.. 
Table 6: Performance of Bayesian Robust Rules with No Policy Inertia

\begin{tabular}{|c|c|c|c|c|c|c|c|}
\hline \multicolumn{2}{|c|}{$\begin{array}{c}\text { Central Bank } \\
\text { Preferences }\end{array}$} & \multicolumn{2}{|c|}{$\begin{array}{l}\text { Policy Rule } \\
\text { Coefficients }\end{array}$} & \multicolumn{3}{|c|}{$\begin{array}{c}\% \Delta \mathcal{L} \\
\text { evaluated in }\end{array}$} & \multirow[t]{2}{*}{$\% \Delta \mathcal{L}^{B}$} \\
\hline$\lambda$ & $\phi$ & $\alpha$ & $\beta$ & NKB & FHP & $\mathrm{RS}$ & \\
\hline \multirow{3}{*}{0.0} & 0.1 & 3.3 & .8 & 176 & 85 & 33 & 76 \\
\hline & 0.5 & 1.6 & .2 & 120 & 56 & 53 & 65 \\
\hline & 1.0 & 1.3 & .1 & 125 & 57 & 50 & 65 \\
\hline \multirow{3}{*}{0.5} & 0.1 & 2.7 & 2.6 & 23 & 23 & 3 & 18 \\
\hline & 0.5 & 1.5 & 1.3 & 56 & 30 & 4 & 29 \\
\hline & 1.0 & 1.2 & .9 & 86 & 32 & 7 & 40 \\
\hline \multirow{3}{*}{1.0} & 0.1 & 2.3 & 3.2 & 26 & 26 & 6 & 20 \\
\hline & 0.5 & 1.4 & 1.8 & 51 & 34 & 4 & 30 \\
\hline & 1.0 & 1.1 & 1.3 & 76 & 38 & 6 & 39 \\
\hline \multirow{3}{*}{2.0} & 0.1 & 1.9 & 3.8 & 34 & 30 & 11 & 24 \\
\hline & 0.5 & 1.2 & 2.3 & 48 & 38 & 7 & 31 \\
\hline & 1.0 & 1.0 & 1.8 & 65 & 43 & 7 & 38 \\
\hline
\end{tabular}

Notes: For each pair of values of the preference parameters $\lambda$ and $\phi$, the corresponding row of this table indicates the parameters and stabilization performance of the optimized 2-parameter $(\rho=0)$ policy rule that minimizes the Bayesian loss function with equal weights. The stabilization performance in each model is measured by the percent deviation of the loss function from the first-best policy of that model. 
Table 7: Performance of Minmax Robust Rules

\begin{tabular}{|c|c|c|c|c|c|c|c|c|c|c|}
\hline \multicolumn{2}{|c|}{$\begin{array}{c}\text { Central Bank } \\
\text { Preferences }\end{array}$} & \multicolumn{3}{|c|}{$\begin{array}{l}\text { Policy Rule } \\
\text { Coefficients }\end{array}$} & \multicolumn{3}{|c|}{$\underset{\text { evaluated in }}{\mathcal{L}}$} & \multicolumn{3}{|c|}{$\begin{array}{c}\% \Delta \mathcal{L} \\
\text { evaluated in }\end{array}$} \\
\hline$\lambda$ & $\phi$ & $\rho$ & $\alpha$ & $\beta$ & NKB & FHP & $\mathrm{RS}$ & NKB & FHP & $\mathrm{RS}$ \\
\hline \multirow{3}{*}{0.0} & 0.1 & .1 & 3.4 & .7 & 3.9 & 5.5 & 5.5 & 171 & 81 & 38 \\
\hline & 0.5 & .3 & 1.5 & .4 & 5.1 & 6.7 & 6.7 & 167 & 71 & 23 \\
\hline & 1.0 & .5 & 1.0 & .3 & 5.9 & 7.5 & 7.5 & 182 & 73 & 17 \\
\hline \multirow{3}{*}{0.5} & 0.1 & .8 & 1.1 & 1.1 & 7.1 & 15.3 & 15.3 & 23 & 12 & 113 \\
\hline & 0.5 & .9 & .5 & .5 & 10.1 & 16.4 & 16.4 & 22 & 9 & 87 \\
\hline & 1.0 & .9 & .3 & .3 & 11.8 & 17.0 & 17.0 & 21 & 7 & 74 \\
\hline \multirow{3}{*}{1.0} & 0.1 & .4 & 2.6 & 3.7 & 7.0 & 20.6 & 20.6 & 15 & 20 & 116 \\
\hline & 0.5 & .9 & .5 & .8 & 12.3 & 21.5 & 21.5 & 27 & 10 & 89 \\
\hline & 1.0 & .9 & .4 & .5 & 15.0 & 22.6 & 22.6 & 24 & 8 & 82 \\
\hline \multirow{3}{*}{2.0} & 0.1 & .6 & .9 & 2.0 & 9.6 & 25.9 & 25.9 & 50 & 19 & 93 \\
\hline & 0.5 & .7 & .6 & 1.3 & 14.4 & 28.8 & 28.8 & 32 & 12 & 83 \\
\hline & 1.0 & .9 & .3 & .8 & 19.8 & 30.5 & 30.5 & 35 & 10 & 78 \\
\hline
\end{tabular}

Notes: For each pair of values of the preference parameters $\lambda$ and $\phi$, the corresponding row of this table indicates the parameters and stabilization performance of the optimized 3-parameter policy rule that minimizes the maximum loss across the three models. 
Table 8: Performance of Bayesian Robust Rules in other Models

\begin{tabular}{|c|c|c|c|c|c|c|}
\hline \multicolumn{2}{|c|}{$\begin{array}{c}\text { Central Bank } \\
\text { Preferences }\end{array}$} & \multicolumn{5}{|c|}{$\begin{array}{c}\% \Delta \mathcal{L} \\
\text { evaluated in }\end{array}$} \\
\hline$\lambda$ & $\phi$ & FM & FRB & MSR & R02 & TMCM \\
\hline \multirow{3}{*}{0.0} & 0.1 & 115 & 55 & 200 & 26 & 46 \\
\hline & 0.5 & 85 & 69 & 190 & 56 & 64 \\
\hline & 1.0 & 77 & 81 & 176 & 69 & 81 \\
\hline \multirow{3}{*}{0.5} & 0.1 & 61 & 42 & 49 & 3 & 28 \\
\hline & 0.5 & 52 & 44 & 45 & 8 & 27 \\
\hline & 1.0 & 48 & 45 & 43 & 14 & 26 \\
\hline \multirow{3}{*}{1.0} & 0.1 & 57 & 50 & 57 & 3 & 33 \\
\hline & 0.5 & 48 & 51 & 52 & 5 & 29 \\
\hline & 1.0 & 43 & 50 & 48 & 8 & 27 \\
\hline \multirow{3}{*}{2.0} & 0.1 & 54 & 62 & 68 & 4 & 43 \\
\hline & 0.5 & 44 & 60 & 62 & 4 & 35 \\
\hline & 1.0 & 39 & 58 & 57 & 6 & 31 \\
\hline
\end{tabular}

Notes: For each pair of values of the preference parameters $\lambda$ and $\phi$, the corresponding row of this table indicates the performance of the Bayesian robust rule reported in Table 3. The stabilization performance in each model is measured by the percent deviation of the loss function from the first-best policy of that model. 
Figure 1: Fault Tolerance Taxonomy $(\% \Delta \mathcal{L})$
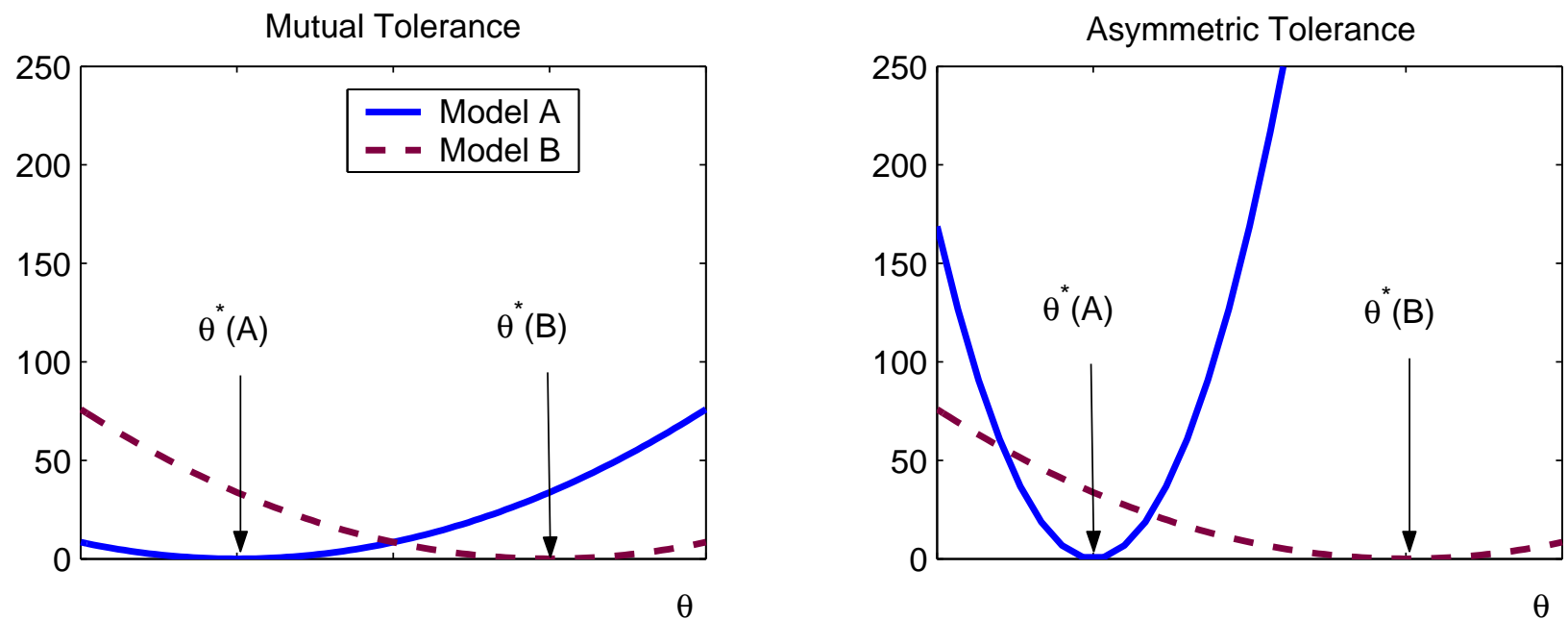$$
\theta
$$
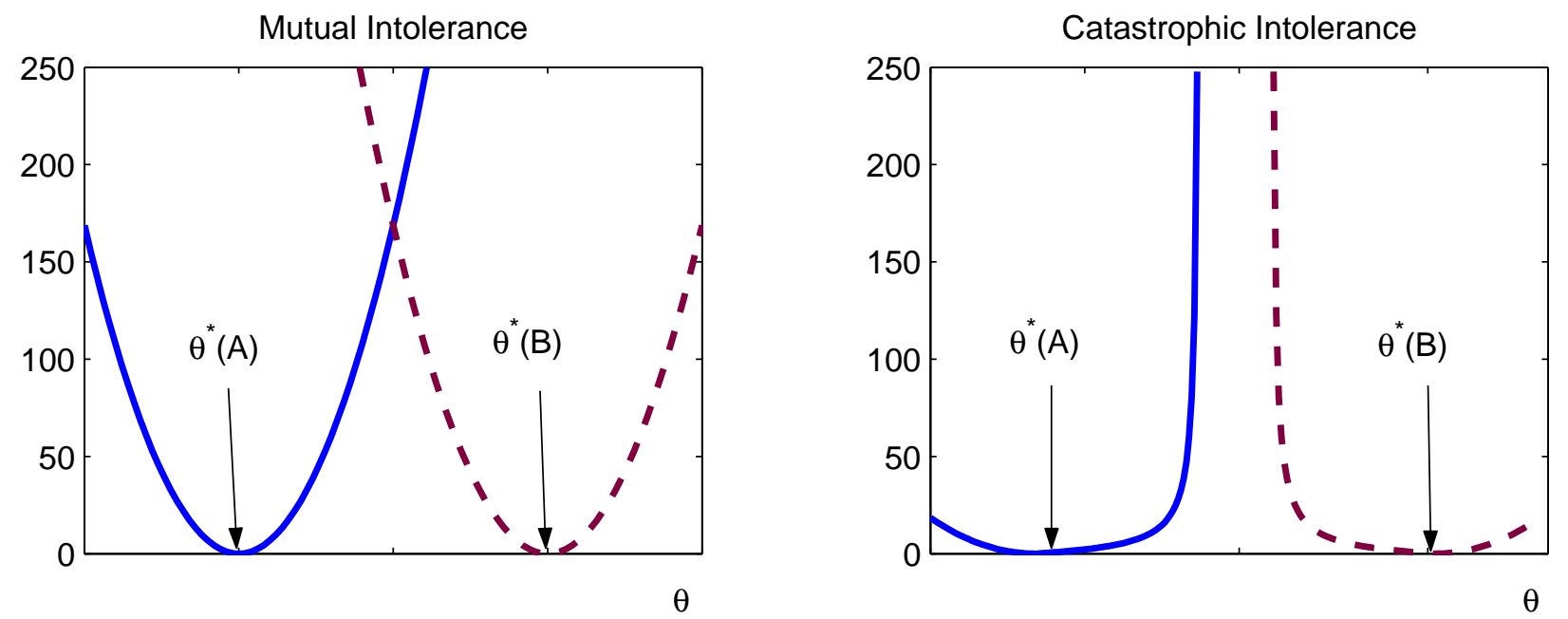

Note: Each line traces out the percent difference in the loss relative to the first-best policy, $\% \Delta \mathcal{L}$, as the policy rule parameter, $\theta$, is varied. The solid line shows the results for model $A$, the dashed line for Model $B$. The optimal value of the policy rule parameter in Model $A$ is denoted by $\theta^{*}(A)$, and for Model $B$ by $\theta^{*}(B)$. 
Figure 2: Fault Tolerances under Strict Inflation Targeting
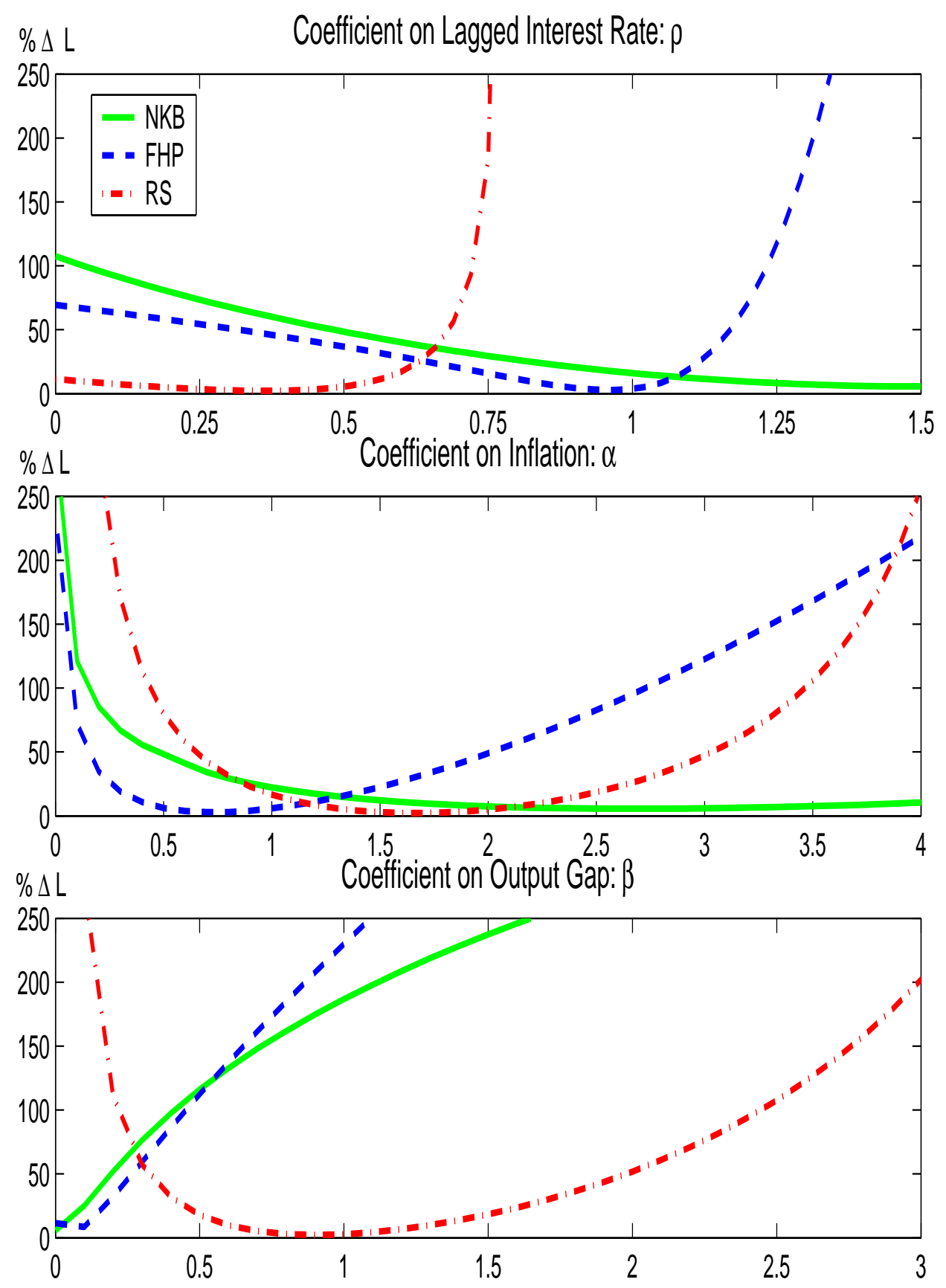

Note: Each line traces out the percent deviation of the loss from the first-best outcome for $\lambda=0$ and $\phi=0.5$, as the specified single parameter of the policy rule is varied, holding the other two parameters fixed at their respective optimized values. 
Figure 3: Placing Equal Weight on Output and Inflation Stability
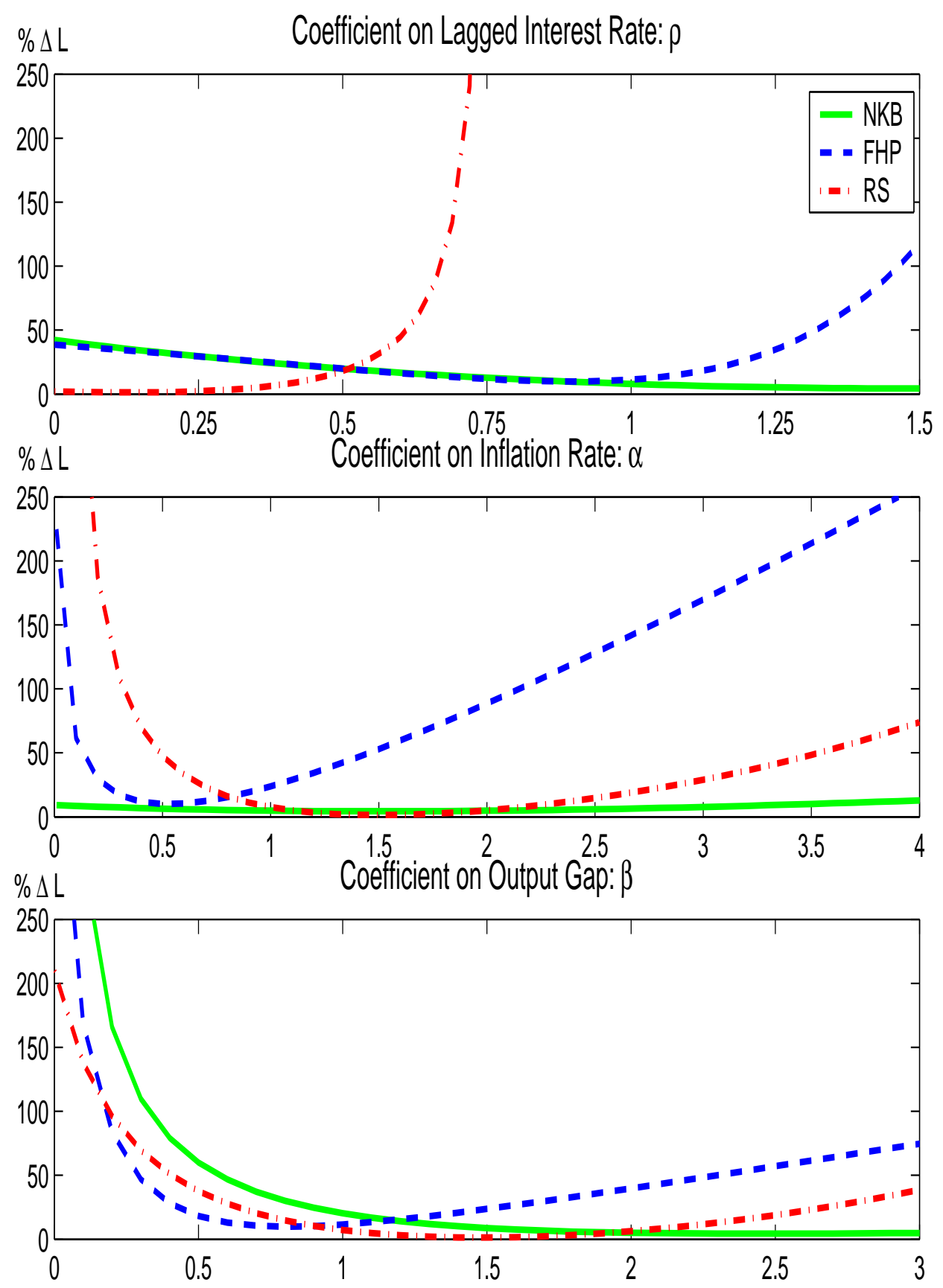

Note: Each line traces out the percent deviation of the loss from the first-best outcome for $\lambda=1$ and $\phi=0.5$, as the specified single parameter of the policy rule is varied, holding the other two parameters fixed at their respective optimized values. 


\section{Appendix}

Tables A1-A3 provide underlying details of the results summarized in Tables 1, 2, and 4, respectively, of the paper. 
Table A1: Detailed Results for Optimal Control Rules

Policymaker

Preferences

Unconditional Variances

$\begin{array}{lllllllllll}\lambda & \phi & y & \pi & \Delta i & y & \pi & \Delta i & y & \pi & \Delta i\end{array}$

Optimal policy for NKB

\begin{tabular}{rrrrrrrrrrr}
\hline \multirow{2}{*}{0.0} & 0.1 & 145.8 & 1.1 & 3.0 & 5055.0 & 20.0 & 753.4 & $\infty$ & $\infty$ & $\infty$ \\
& 0.5 & 107.5 & 1.6 & 0.5 & 4590.4 & 52.9 & 193.6 & $\infty$ & $\infty$ & $\infty$ \\
& 1.0 & 97.4 & 1.8 & 0.2 & 4312.3 & 77.1 & 101.7 & $\infty$ & $\infty$ & $\infty$ \\
\hline \multirow{3}{*}{0.5} & 0.1 & 1.2 & 4.2 & 10.1 & 22.3 & 6.8 & 41.5 & $\infty$ & $\infty$ & $\infty$ \\
& 0.5 & 4.0 & 4.2 & 4.0 & 33.0 & 7.7 & 9.5 & $\infty$ & $\infty$ & $\infty$ \\
& 1.0 & 6.2 & 4.3 & 2.3 & 44.0 & 9.2 & 4.9 & $\infty$ & $\infty$ & $\infty$ \\
\hline \multirow{3}{*}{1.0} & 0.1 & 0.4 & 4.4 & 12.8 & 9.5 & 8.7 & 378.1 & $\infty$ & $\infty$ & $\infty$ \\
& 0.5 & 2.0 & 4.5 & 6.3 & 11.2 & 8.7 & 75.3 & $\infty$ & $\infty$ & $\infty$ \\
& 1.0 & 3.6 & 4.6 & 3.9 & 17.3 & 9.7 & 18.0 & $\infty$ & $\infty$ & $\infty$ \\
\hline \multirow{3}{*}{2.0} & 0.1 & 0.2 & 4.6 & 14.8 & 24.2 & 11.5 & 9.4 & $\infty$ & $\infty$ & $\infty$ \\
& 0.5 & 0.9 & 4.7 & 9.0 & 5.5 & 11.1 & 131.9 & $\infty$ & $\infty$ & $\infty$ \\
& 1.0 & 1.9 & 4.8 & 6.1 & 13.0 & 14.0 & 18.0 & $\infty$ & $\infty$ & $\infty$ \\
\hline
\end{tabular}

Optimal policy for FHP

\begin{tabular}{rrrrrrrrrrr}
\hline \multirow{2}{*}{0.0} & 0.1 & 66.2 & 3.9 & 0.0 & 160.5 & 2.6 & 4.7 & $\infty$ & $\infty$ & $\infty$ \\
& 0.5 & 71.0 & 4.4 & 0.0 & 103.1 & 3.3 & 1.2 & $\infty$ & $\infty$ & $\infty$ \\
& 1.0 & 73.2 & 4.6 & 0.0 & 87.3 & 3.7 & 0.7 & $\infty$ & $\infty$ & $\infty$ \\
\hline \multirow{3}{*}{0.5} & 0.1 & 11.5 & 5.0 & 1.4 & 9.0 & 8.5 & 7.0 & 9.9 & 4.0 & 50.0 \\
& 0.5 & 23.8 & 5.1 & 0.3 & 11.0 & 8.5 & 2.2 & 8.5 & 4.3 & 7.5 \\
& 1.0 & 29.8 & 5.2 & 0.1 & 12.2 & 8.5 & 1.3 & 7.3 & 4.9 & 3.8 \\
\hline \multirow{3}{*}{1.0} & 0.1 & 7.5 & 5.0 & 2.5 & 5.8 & 10.2 & 11.5 & 15.0 & 4.7 & 200.4 \\
& 0.5 & 18.1 & 5.1 & 0.6 & 7.5 & 10.2 & 3.6 & 7.4 & 4.8 & 13.5 \\
& 1.0 & 24.0 & 5.2 & 0.3 & 8.5 & 10.2 & 2.2 & 10.3 & 5.3 & 7.2 \\
\hline \multirow{3}{*}{2.0} & 0.1 & 4.5 & 5.0 & 4.1 & 3.8 & 12.4 & 18.7 & $\infty$ & $\infty$ & $\infty$ \\
& 0.5 & 13.0 & 5.1 & 1.2 & 5.1 & 12.4 & 5.9 & 7.5 & 5.6 & 31.5 \\
& 1.0 & 18.2 & 5.1 & 0.6 & 5.9 & 12.4 & 3.6 & 5.5 & 7.6 & 12.3 \\
\hline
\end{tabular}

Optimal policy for $R S$

\begin{tabular}{rrrrrrrrrrr}
\hline \multirow{3}{*}{0.0} & 0.1 & 7.6 & 3.6 & 9.8 & 22.3 & 6.6 & 8.6 & 8.9 & 3.3 & 6.9 \\
& 0.5 & 9.8 & 3.7 & 6.1 & 20.3 & 7.2 & 3.6 & 8.1 & 4.3 & 2.4 \\
& 1.0 & 11.3 & 3.8 & 4.7 & 19.6 & 7.4 & 2.5 & 7.9 & 4.9 & 1.6 \\
\hline \multirow{3}{*}{0.5} & 0.1 & 4.3 & 4.0 & 12.8 & 14.5 & 8.5 & 14.2 & 5.2 & 3.8 & 7.6 \\
& 0.5 & 6.8 & 4.0 & 8.2 & 15.3 & 8.6 & 5.0 & 5.6 & 4.7 & 2.5 \\
& 1.0 & 8.5 & 4.0 & 6.4 & 15.6 & 8.6 & 3.3 & 5.8 & 5.2 & 1.6 \\
\hline \multirow{3}{*}{1.0} & 0.1 & 3.3 & 4.1 & 14.0 & 12.0 & 9.5 & 18.6 & 4.3 & 4.3 & 9.1 \\
& 0.5 & 5.5 & 4.1 & 9.5 & 13.2 & 9.5 & 6.3 & 4.8 & 5.1 & 2.8 \\
& 1.0 & 7.1 & 4.0 & 7.4 & 13.8 & 9.4 & 4.0 & 5.1 & 5.6 & 1.8 \\
\hline \multirow{3}{*}{2.0} & 0.1 & 2.5 & 4.2 & 15.4 & 9.8 & 10.9 & 26.0 & 3.6 & 5.0 & 12.1 \\
& 0.5 & 4.3 & 4.2 & 11.0 & 11.1 & 10.7 & 8.5 & 4.1 & 5.8 & 3.5 \\
& 1.0 & 5.6 & 4.2 & 8.9 & 11.7 & 10.6 & 5.3 & 4.4 & 6.3 & 2.1 \\
\hline \hline
\end{tabular}


Table A2: Detailed Results for Optimized 3-Parameter Rules

Policymaker Unconditional Variances

Preferences Evaluated in NKB Evaluated in FHP Evaluated in RS

\begin{tabular}{lllllllllll}
$\lambda$ & $\phi$ & $y$ & $\pi$ & $\Delta i$ & $y$ & $\pi$ & $\Delta i$ & $y$ & $\pi$ & $\Delta i$ \\
\hline
\end{tabular}

Optimized policy for $N K B$

\begin{tabular}{|c|c|c|c|c|c|c|c|c|c|c|}
\hline \multirow{3}{*}{0.0} & 0.1 & 140.2 & 1.3 & 3.0 & 1774.6 & 12.4 & 91.8 & $\infty$ & $\infty$ & $\infty$ \\
\hline & 0.5 & 100.7 & 1.7 & 0.6 & 1336.8 & 28.2 & 16.6 & $\infty$ & $\infty$ & $\infty$ \\
\hline & 1.0 & 91.0 & 2.0 & 0.3 & 1151.6 & 36.9 & 7.4 & $\infty$ & $\infty$ & $\infty$ \\
\hline \multirow{3}{*}{0.5} & 0.1 & 1.1 & 4.5 & 10.4 & 9.4 & 10.2 & 31.5 & $\infty$ & $\infty$ & $\infty$ \\
\hline & 0.5 & 4.1 & 4.5 & 4.1 & 22.1 & 8.3 & 7.3 & $\infty$ & $\infty$ & $\infty$ \\
\hline & 1.0 & 6.6 & 4.6 & 2.3 & 35.3 & 7.5 & 4.0 & $\infty$ & $\infty$ & $\infty$ \\
\hline \multirow{3}{*}{1.0} & 0.1 & 0.4 & 4.7 & 13.1 & 3.8 & 14.9 & 60.8 & $\infty$ & $\infty$ & $\infty$ \\
\hline & 0.5 & 2.0 & 4.8 & 6.6 & 10.0 & 12.2 & 13.3 & $\infty$ & $\infty$ & $\infty$ \\
\hline & 1.0 & 3.8 & 4.8 & 4.1 & 17.0 & 10.6 & 7.0 & $\infty$ & $\infty$ & $\infty$ \\
\hline \multirow{3}{*}{2.0} & 0.1 & 0.1 & 4.9 & 15.1 & 1.5 & 21.5 & 115.3 & $\infty$ & $\infty$ & $\infty$ \\
\hline & 0.5 & 0.9 & 4.9 & 9.5 & 4.6 & 17.5 & 25.4 & $\infty$ & $\infty$ & $\infty$ \\
\hline & 1.0 & 1.9 & 4.9 & 6.5 & 8.2 & 15.1 & 13.2 & $\infty$ & $\infty$ & $\infty$ \\
\hline \multicolumn{11}{|c|}{ Optimized policy for FHP } \\
\hline \multirow{3}{*}{0.0} & 0.1 & 51.1 & 2.3 & 0.7 & 149.9 & 2.6 & 4.9 & $\infty$ & $\infty$ & $\infty$ \\
\hline & 0.5 & 47.4 & 2.7 & 0.2 & 95.9 & 3.4 & 1.3 & $\infty$ & $\infty$ & $\infty$ \\
\hline & 1.0 & 47.1 & 2.8 & 0.1 & 81.2 & 3.8 & 0.7 & $\infty$ & $\infty$ & $\infty$ \\
\hline \multirow{3}{*}{0.5} & 0.1 & 4.1 & 4.3 & 5.5 & 10.6 & 9.4 & 5.5 & $\infty$ & $\infty$ & $\infty$ \\
\hline & 0.5 & 9.1 & 4.3 & 2.2 & 12.7 & 9.2 & 1.7 & 31.3 & 8.0 & 6.5 \\
\hline & 1.0 & 12.1 & 4.3 & 1.4 & 13.8 & 9.1 & 1.0 & 22.6 & 8.9 & 2.4 \\
\hline \multirow{3}{*}{1.0} & 0.1 & 2.2 & 4.5 & 7.8 & 6.7 & 11.6 & 10.2 & $\infty$ & $\infty$ & $\infty$ \\
\hline & 0.5 & 5.6 & 4.5 & 3.7 & 8.5 & 11.4 & 3.1 & 53.5 & 8.7 & 30.2 \\
\hline & 1.0 & 7.9 & 4.5 & 2.5 & 9.5 & 11.3 & 1.9 & 15.3 & 6.9 & 3.9 \\
\hline \multirow{3}{*}{2.0} & 0.1 & 1.1 & 4.7 & 9.9 & 4.3 & 14.3 & 17.6 & $\infty$ & $\infty$ & $\infty$ \\
\hline & 0.5 & 3.3 & 4.6 & 5.5 & 5.7 & 14.1 & 5.5 & $\infty$ & $\infty$ & $\infty$ \\
\hline & 1.0 & 5.0 & 4.6 & 3.9 & 6.6 & 13.9 & 3.3 & 31.9 & 8.6 & 20.9 \\
\hline
\end{tabular}

Optimized policy for $R S$

\begin{tabular}{rrrrrrrrrrr}
\hline \multirow{3}{*}{0.0} & 0.1 & 6.3 & 3.7 & 11.6 & 21.6 & 6.6 & 10.3 & 9.0 & 3.4 & 7.0 \\
& 0.5 & 8.9 & 3.8 & 6.7 & 20.3 & 7.1 & 3.9 & 8.2 & 4.4 & 2.5 \\
& 1.0 & 10.6 & 3.8 & 4.9 & 19.8 & 7.3 & 2.7 & 7.9 & 5.0 & 1.6 \\
\hline \multirow{3}{*}{0.5} & 0.1 & 3.7 & 4.0 & 14.4 & 13.6 & 8.6 & 16.2 & 5.3 & 4.0 & 6.9 \\
& 0.5 & 6.2 & 4.0 & 9.1 & 15.0 & 8.6 & 5.6 & 5.7 & 4.8 & 2.5 \\
& 1.0 & 7.9 & 4.0 & 6.8 & 15.6 & 8.6 & 3.6 & 5.8 & 5.3 & 1.6 \\
\hline \multirow{3}{*}{1.0} & 0.1 & 2.9 & 4.2 & 15.5 & 11.2 & 9.7 & 20.5 & 4.6 & 4.5 & 7.3 \\
& 0.5 & 5.1 & 4.1 & 10.5 & 12.8 & 9.5 & 7.0 & 4.9 & 5.2 & 2.8 \\
& 1.0 & 6.6 & 4.1 & 8.0 & 13.6 & 9.4 & 4.4 & 5.1 & 5.7 & 1.8 \\
\hline \multirow{3}{*}{2.0} & 0.1 & 2.3 & 4.3 & 16.6 & 9.0 & 11.1 & 27.2 & 3.9 & 5.3 & 7.9 \\
& 0.5 & 4.0 & 4.2 & 12.1 & 10.6 & 10.7 & 9.2 & 4.2 & 5.9 & 3.4 \\
& 1.0 & 5.3 & 4.2 & 9.6 & 11.5 & 10.6 & 5.7 & 4.4 & 6.4 & 2.1 \\
\hline
\end{tabular}


Table A3: Detailed Results for Bayesian Robust 3-Parameter Rules

\begin{tabular}{|c|c|c|c|c|c|c|c|c|c|c|}
\hline \multirow{2}{*}{\multicolumn{2}{|c|}{$\begin{array}{c}\text { Policymaker } \\
\text { Preferences }\end{array}$}} & \multicolumn{9}{|c|}{ Unconditional Variances } \\
\hline & & \multicolumn{3}{|c|}{ Evaluated in NKB } & \multicolumn{3}{|c|}{ Evaluated in FHP } & \multicolumn{3}{|c|}{ Evaluated in RS } \\
\hline$\lambda$ & $\phi$ & $y$ & $\pi$ & $\Delta i$ & $y$ & $\pi$ & $\Delta i$ & $y$ & $\pi$ & $\Delta i$ \\
\hline \multirow{3}{*}{0.0} & 0.1 & 15.4 & 3.2 & 7.1 & 34.7 & 5.3 & 4.6 & 16.3 & 4.7 & 4.3 \\
\hline & 0.5 & 26.1 & 3.2 & 2.3 & 35.1 & 5.5 & 1.6 & 13.8 & 6.9 & 1.4 \\
\hline & 1.0 & 32.0 & 3.2 & 1.3 & 35.9 & 5.6 & 1.2 & 13.0 & 8.1 & 0.9 \\
\hline \multirow{3}{*}{0.5} & 0.1 & 3.3 & 4.2 & 10.1 & 11.1 & 9.4 & 9.7 & 5.7 & 4.2 & 7.0 \\
\hline & 0.5 & 6.8 & 4.2 & 4.6 & 11.9 & 9.5 & 3.0 & 6.6 & 5.3 & 2.1 \\
\hline & 1.0 & 9.2 & 4.2 & 2.9 & 12.4 & 9.6 & 1.8 & 7.0 & 6.1 & 1.3 \\
\hline \multirow{3}{*}{1.0} & 0.1 & 2.1 & 4.4 & 12.0 & 8.0 & 11.3 & 14.5 & 4.5 & 5.0 & 10.1 \\
\hline & 0.5 & 4.7 & 4.3 & 6.2 & 9.0 & 11.2 & 4.5 & 5.3 & 5.9 & 3.1 \\
\hline & 1.0 & 6.7 & 4.3 & 4.1 & 9.6 & 11.2 & 2.7 & 5.7 & 6.5 & 1.8 \\
\hline \multirow{3}{*}{2.0} & 0.1 & 1.4 & 4.5 & 13.9 & 5.9 & 13.5 & 22.3 & 3.8 & 6.3 & 15.3 \\
\hline & 0.5 & 3.0 & 4.5 & 8.4 & 6.9 & 13.4 & 7.1 & 4.3 & 7.1 & 4.8 \\
\hline & 1.0 & 4.5 & 4.5 & 6.0 & 7.4 & 13.3 & 4.2 & 4.7 & 7.6 & 2.8 \\
\hline
\end{tabular}




\section{References}

Amato, Jeffery D. and Thomas Laubach, "Estimation and Control of an Optimization-Based Model with Sticky Prices and Wages," Journal of Economic Dynamics and Control, May 2003, $27(7), 1181-1215$.

Anderson, Gary and George Moore, "A Linear Algebraic Procedure for Solving Linear Perfect Foresight Models," Economics Letters, 1985, 17 (3), 247-252.

Becker, Robin G., Barry Dwolatsky, Elias Karakitsos, and Berc Rustem, "The Simulataneous Use of Rival Models in Policy Optimisation," Economic Journal, June 1986, 96 (382), 425-48.

Brainard, William, "Uncertainty and the Effectiveness of Policy," American Economic Review (Papers and Procedings), May 1967, 57 (2), 411-425.

Brayton, Flint, Eileen Mauskopf, David Reifschneider, Peter Tinsley, and John Williams, "The Role of Expectations in the FRB/US Macroeconomic Model," Federal Reserve Bulletin, 1997, 83 (4), 227-245.

Buiter, Willem H. and Ian Jewitt, "Staggered Wage Setting with Real Wage Relativities: Variations on a Theme by Taylor," The Manchester School, 1981, 49 (3), 211-228.

Caplin, Andrew and John Leahy, "Monetary Policy as a Process of Search," American Economic Review, September 1996, 86 (4), 689-702.

Chow, Gregory C., "The Effect of Uncertainty on Optimal Control Policies," International Economic Review, October 1973, 14 (3), 632-645.

Christiano, Lawrence J., Martin Eichenbaum, and Charles L. Evans, "Nominal Rigidities and the Dynamic Effects of a Shock to Monetary Policy," July 2001. NBER Working Paper 8403 .

Christodoulakis, Nico, David Kemball-Cook, and Paul Levine, "The Design of Economic Policy under Model Uncertainty," Computational Economics, November 1993, 6 (3-4), 219-40.

Clarida, Richard, Jordi Gali, and Mark Gertler, "The Science of Monetary Policy: A New Keynesian Perspective," Journal of Economic Literature, December 1999, 37 (4), 1661-1707.

Erceg, Christopher J. and Andrew T. Levin, "Optimal Monetary Policy with Durable and Non-Durable Goods," September 2002. European Central Bank Working Paper 179.

Finan, Frederico and Robert Tetlow, "Optimal Control of Large, Forward-Looking Models: Efficient Solutions and Two Examples," October 2001. Board of Governors of the Federal Reserve System Finance and Economics Discussion Series Working Paper, 1999-51.

Frankel, Jeffery A. and Katherine Rockett, "International Macroeconomic Policy Coordination when Policymakers Do Not Agree on the True Model," American Economic Review, June 1988, 78 (3), 318-40.

Fuhrer, Jeffrey C., "Inflation/Output Variance Trade-Offs and Optimal Monetary Policy," Journal of Money, Credit and Banking, May 1997a, 29 (2), 214-34.

_ , "Towards a Compact, Empirically-Verified Rational Expectations Model for Monetary Policy Analysis," Carnegie Rochester Conference Series on Public Policy, 1997b, 47, 197-230.

"Habit Formation in Consumption and Its Implications for Monetary-Policy Models," American Economic Review, June 2000, 90 (3), 367-90. 
and George Moore, "Inflation Persistence," Quarterly Journal of Economics, February 1995, $110(1), 127-59$.

Giannoni, Marc P., "Robust Optimal Monetary Policy In a Forward-Looking Model with Parameter and Shock Uncertainty," January 2001. Manuscript, Federal Reserve Bank of New York.

, "Does Model Uncertainty Justify Caution? Robust Optimal Monetary Policy in a ForwardLooking Model," Macroeconomic Dynamics, 2002, 6 (1), 111-144.

and Michael Woodford, "Optimal Interest-Rate Rules: I. General Theory," August 2002a. Manuscript, Princeton University.

and __ "Optimal Interest-Rate Rules: II. Applications," August 2002b. Manuscript, Princeton University.

and __ , "Optimal Inflation Targeting Rules," in Michael Woodford, ed., Inflation Targeting, Chicago: University of Chicago Press, 2003. forthcoming.

Goodfriend, Marvin and Robert King, "The New Neoclassical Synthesis and the Role of Monetary Policy," in Ben S. Bernanke and Julio J. Rotemberg, eds., NBER Macroeconomics Annual 1997, Cambridge, MA: The MIT Press, 1997, pp. 231-283.

Goodhart, Charles A. E., "Why Do the Monetary Authorities Smooth Interest Rates?," 1996. London School of Econonmics and Political Science Financial Markets Group, Special Paper no. 81 .

Hansen, Lars P. and Thomas J. Sargent, Recursive Linear Models of Dynamic Economies, Chicago: University of Chicago Press, 1998.

and __ , "Robust Control and Model Uncertainty in Economics," October 2002. manuscript, New York University.

Holtham, Gerald and Andrew Hughes-Hallett, "International Macroeconomic Policy Coordination when Policymakers Do Not Agree on the True Model: Comment," American Economic Review, September 1992, 82 (4), 1043-56.

IEEE Computer Society, IEEE Standard Computer Dictionary: A Compilation of IEEE Standard Computer Glossaries, New York, NY: Institute of Electrical and Electronics Engineers, 1990.

Karakitsos, E. and B. Rustem, "Optimally Derived Fixed Rules and Indicators," Journal of Economic Dynamics and Control, October 1984, 8 (1), 33-64.

Kerr, W. and Robert G. King, "Limits on Interest Rate Rules in an IS Model," Federal Reserve Bank of Richmond Economic Quarterly, Spring 1996, 82 (2), 47-75.

King, Mervyn, "Changes in UK Monetary Policy: Rules and Discretion in Practice," Journal of Monetary Economics, June 1997, 39 (1), 81-97.

King, Robert and Alexander Wolman, "What Should the Monetary Authority Do When Prices are Sticky?," in John B. Taylor, ed., Monetary Policy Rules, Chicago: University of Chicago Press, 1999, pp. 349-398.

Laubach, Thomas and John C. Williams, "Measuring the Natural Rate of Interest," Review of Economics and Statistics, 2003. Forthcoming.

Levin, Andrew T. and John C. Williams, "Parameter Uncertainty and the Central Bank's Objective Function," July 2003. Federal Reserve Bank of San Francisco, manuscript. 
_ Volker Wieland, and John C. Williams, "Robustness of Simple Monetary Policy Rules under Model Uncertainty," in John B. Taylor, ed., Monetary Policy Rules, Chicago: University of Chicago Press, 1999, pp. 263-299.

and __ , "The Performance of Forecast-Based Monetary Policy Rules under Model Uncertainty," American Economic Review, June 2003, 93 (3), 622-645.

Lowe, Philip and Luci Ellis, "The Smoothing of Official Interest Rates," in Philip Lowe, ed., Monetary Policy and Inflation Targeting: Procedings of a Conference, Sydney: Reserve Bank of Australia, 1997, pp. 286-312.

McCallum, Bennett T., "Robustness Properties of a Rule for Monetary Policy," Carnegie Rochester Conference Series on Public Policy, Autumn 1988, 29, 173-204.

_ _ "Issues in the Design of Monetary Policy Rules," in John B. Taylor and Michael Woodford, eds., Handbook of Macroeconomics, Vol. 1c, Amsterdam: Elsevier Science, North-Holland, 1999, pp. 1483-1530.

_ , "Should Monetary Policy Respond Strongly to Output Gaps?," American Economic Review, May 2001 (Papers and Procedings), 91 (2), 258-262.

Meyer, Laurence H., Eric T. Swanson, and Volker W. Wieland, "NAIRU Uncertainty and Nonlinear Policy Rules," January 2001. FEDS Working Paper 2001-1, Board of Governors of the Federal Reserve System.

Nelson, Edward and K. Nikolov, "UK inflation in the 1970s and 1980s: the role of output gap mismeasurement," 2002. Bank of England Working Paper 148 and CEPR Discussion Paper 2999.

Onatski, Alexei, "Robust Monetary Policy under Model, Data, and Shock Uncertainty in a Small Forward Looking Model of the U.S. Economy," November 2001. manuscript, Columbia University.

and James H. Stock, "Robust Monetary Policy Under Model Uncertainty in a Small Model of the U.S. Economy," Macroeconomic Dynamics, February 2002, 6 (1), 85-110.

_ and Noah Williams, "Modeling Model Uncertainty," Journal of the European Economic Association, 2003, Forthcoming.

Orphanides, Athanasios and John C. Williams, "Robust Monetary Policy Rules with Unknown Natural Rates," Brookings Papers on Economic Activity, 2002, 2, 63-145.

and Simon van Norden, "The Unreliability of Output Gap Estimates in Real Time," Review of Economics and Statistics, November 2002, 84 (4), 569-583.

and Volker Wieland, "Price Stability and Monetary Policy Effectiveness when Nominal Interest Rates are Bounded at Zero," 1998. FEDS Working Paper 1998-35, Board of Governors of the Federal Reserve System.

, Richard D. Porter, David Reifschneider, Robert Tetlow, and Frederico Finan, "Errors in the Measurement of the Output Gap and the Design of Monetary Policy," Journal of Economics and Business, Jan.-April 2000, 52 (1-2), pp. 117-41.

Rotemberg, Julio J. and Michael Woodford, "An Optimization-Based Econometric Framework for the Evaluation of Monetary Policy," in Ben S. Bernanke and Julio J. Rotemberg, eds., NBER Macroeconomics Annual 1997, Cambridge, MA: The MIT Press, 1997, pp. 297-346.

and __ , "Interest-Rate Rules in an Estimated Sticky Price Model," in John B. Taylor, ed., Monetary Policy Rules, Chicago: University of Chicago Press, 1999, pp. 57-119. 
Rudebusch, Glenn D., "Is the Fed Too Timid? Monetary Policy in an Uncertain World," Review of Economics and Statistics, May 2001, 83 (2), 203-217.

, "Assessing Nominal Income Rules for Monetary policy with Model and Data Uncertainty," Economic Journal, April 2002, 112 (489), 402-432.

and Lars E. O. Svensson, "Policy Rules for Inflation Targeting," in John B. Taylor, ed., Monetary Policy Rules, Chicago: University of Chicago Press, 1999, pp. 203-253.

Sargent, Thomas, "Discussion of 'Policy Rules for Open Economies'," in John B. Taylor, ed., Monetary Policy Rules, Chicago: University of Chicago Press, 1999, pp. 145-154.

Sims, Christopher A., "Pitfalls of a Minimax Approach to Model Uncertainty," American Economic Association Papers and Proceedings, May 2001, 91 (2), 51-54.

Smets, Frank, "Output Gap Uncertainty: Does it matter for the Taylor Rule?," in B. Hunt and A. Orr, eds., Monetary Policy under Uncertainty, Wellington, New Zealand: Reserve Bank of New Zealand, 1999, pp. 10-29.

Staiger, Douglas, James Stock, and Mark Watson, "How Precise are Estimates of the Natural Rate of Unemployment?," in Christina Romer and David Romer, eds., Reducing Inflation: Motivation and Strategy, Chicago: University of Chicago Press, 1997, pp. 195-242.

Svensson, Lars E. O., "Inflation Forecast Targeting: Implementing and Monitoring Inflation Targets," European Economic Review, June 1997, 41 (6), 1111-1146.

, "What is wrong with Taylor Rules? Using Judgment in Monetary Policy through Targeting Rules," Journal of Economic Literature, 2003, 41 (2), 426-477.

and Michael Woodford, "Implementing Optimal Policy through Inflation-Forecast Targeting," in Michael Woodford, ed., Inflation Targeting, Chicago: University of Chicago Press, 2003a. forthcoming.

and _ , "Indicator Variables for Optimal Policy," Journal of Monetary Economics, 2003b, $50(3), 691-720$.

Taylor, John B., "Discretion versus Policy Rules in Practice," Carnegie Rochester Conference Series on Public Policy, 1993, 39, 195-214.

__ Macroeconomic Policy in a World Economy, New York: Norton, 1993.

, "Introduction," in John B. Taylor, ed., Monetary Policy Rules, Chicago: University of Chicago Press, 1999, pp. 1-14.

Tetlow, Robert and Peter von zur Muehlen, "Robust Monetary Policy with Misspecified Models: Does Model Uncertainty Always Call for Attenuated Policy?," Journal of Economic Dynamics and Control, June-July 2001, 25 (6-7), 911-949.

Williams, John C., "Simple Rules for Monetary Policy," Federal Reserve Bank of San Francisco Economic Review, 2003, pp. 1-12.

Woodford, Michael, "Optimal Monetary Policy Inertia," Manchester School, Supplement 1999, $67,1-35$.

"A Neo-Wicksellian Framework for the Analysis of Monetary Policy," September 2000. manuscript, Princeton University. 